\author{
UNIVERSIDADE DE BRASÍLIA \\ FACULDADE DE CIÊNCIAS DA SAÚDE \\ PROGRAMA DE PÓS-GRADUAÇÃO EM SAÚDE COLETIVA
}

SUETÔNIO QUEIROZ DE ARAÚJO

\title{
A ASSISTÊNCIA FARMACÊUTICA NAS REDES DE ATENÇÃO À SAÚDE: O PLANEJAMENTO E OS SERVIÇOS NO SUS
}

Dissertação apresentada como requisito parcial para a obtenção do Título de Mestre em Saúde Coletiva pelo Programa de Pós- Graduação em Saúde Coletiva da Universidade de Brasília.

Orientador(a): Prof. Dra. Noemia Urruth Leão Tavares

BRASÍLIA 


\title{
A ASSISTÊNCIA FARMACÊUTICA NAS REDES DE ATENÇÃO À SAÚDE: O PLANEJAMENTO E OS SERVIÇOS NO SUS
}

\begin{abstract}
Dissertação apresentada como requisito parcial para a obtenção do Título de Mestre em Saúde Coletiva pelo Programa de Pós- Graduação em Saúde Coletiva da Universidade de Brasília.
\end{abstract}

Aprovado em 01 de Outubro de 2014

\section{BANCA EXAMINADORA}

\author{
Noemia Urruth Leão Tavares \\ Universidade de Brasília - UnB \\ Carmen Cecília de Campos Lavras \\ Universidade Estadual de Campinas - UNICAMP \\ Helena Eri Shimizu \\ Universidade de Brasília - UnB \\ Maria de Fátima Souza \\ Suplente \\ Universidade de Brasília - UnB
}


Dedico esta dissertação a minha Mãe, Maria do Socorro Queiroz, uma educadora, nossa guerreira na família e o meu exemplo de luta e superação diária, com quem compartilho este meu sonho e a encorajo para também realizá-lo em breve. 


\section{AGRADECIMENTOS}

À minha esposa Carolina, minha Preta, sempre presente e companheira nos momentos felizes e também nos tristes, mas que aguenta as chatices e molecagens deste seu esposo turrão, mas apaixonado. Obrigado por fazer parte da minha vida.

Aos meus irmãos e irmãs que a quilômetros de distância, sempre estarão comigo em minhas orações e em meu coração.

À minha orientadora, Prof. ${ }^{a}$ Dr. ${ }^{a}$ Noemia Urruth Leão Tavares, pela paciência e disposição para contribuir sempre que solicitada, mesmo nas situações mais adversas, sempre com uma fala tranquila e conciliadora, contribuindo com esse e com tantos outros trabalhos que acabamos por fazê-los concomitantemente as atividades do ministério e da universidade.

Aproveito ainda para agradecer a banca examinadora, à Prof. ${ }^{a}$ Dr..$^{\text {a }}$ Carmen Cecília de Campos Lavras, sempre disponível a capitanear lutadores pelo SUS e compartilhar seus conhecimentos em prol da saúde pública deste país, e a Prof. ${ }^{a}$ Dr. ${ }^{\text {a }}$ Helena Eri Shimizu e Prof. ${ }^{\text {a }}$ Dr. ${ }^{\text {a }}$ Maria de Fátima Souza que acompanharam mais de perto esses dois anos de estudos e como docentes contribuíram diretamente para as reflexões neste retorno à minha vida acadêmica. Obrigado a todas por aceitarem o convite e contribuírem com as reflexões para a construção deste trabalho.

À minha chefa, antes colega, mas hoje amiga Dr. ${ }^{a}$ Karen Sarmento Costa, sonhadora e realizadora, e ao meu também querido mestre Prof. Orlando Soeiro, não esquecerei o quanto ambos me incentivaram e persistiram até conseguirem esse meu retorno ao mundo da pesquisa e da academia, sem é claro deixar de lado a nossa loucura diária na gestão pública, uma paixão e um permanente desafio no SUS.

Aos colegas de trabalho Marcela Amaral, Lilian Zolikoffer, Thalison Henrique, Manoel Santos, Vera Thierling, Brunna Rafhaelle que dividiram comigo o seu dia a dia entre atividades no Ministério da Saúde e inúmeras viagens pelo país a fora, sem dúvida vocês acompanharam bem de perto toda essa etapa da minha vida profissional e acadêmica, a todos (as) vocês meu muito obrigado pela paciência e por compartilharem comigo um pouco da solidão daqueles que vem para a "terra de 
todos os brasileiros" e que ao chegarem acabam por focar suas vidas no trabalho e estudo, longe daqueles que ama.

A toda a equipe da Coordenação Geral da Assistência Farmacêutica Básica pela compreensão e paciência frente às dificuldades, mas especialmente pelo empenho em prol do SUS, meu muito obrigado a todos (as).

À minha equipe incansável do Projeto QualiSUS-Rede do Ministério da Saúde e da Unidade de Gestão, mas especialmente aos colegas farmacêuticos (as) que contribuíram, a muitas mãos, com todo esse trabalho de pesquisa, desde a construção dos instrumentos até as discussões e análises preliminares dos resultados, meu muito obrigado e minha admiração.

Por fim, aos gestores e técnicos dos municípios da 5ª Região de Saúde, bem como do Conselho de Secretarias Municipais de Saúde (COSEMS-AL) e da Secretaria de Estado da Saúde de Alagoas, por fazerem parte da minha história na saúde pública e por contribuírem voluntariamente com a pesquisa, o meu muito obrigado e sincero respeito a todos (as) pelo trabalho diário na defesa do Sistema Único de Saúde. 
Lutar com palavras é a luta mais vã.

Entanto lutamos mal rompe a manhã.

São muitas, eu pouco.

(...) Lutar com palavras parece sem fruto.

Não têm carne e sangue...

Entretanto, luto.

(Carlos Drummond de Andrade) 


\section{RESUMO}

$\mathrm{Na}$ perspectiva da assistência farmacêutica e na tentativa de atender o preconizado para o planejamento em saúde no SUS, observando as diretrizes para as Redes de Atenção à Saúde e as orientações da Organização Mundial da Saúde (OMS) para as chamadas Redes Integradas de Serviços de Saúde (RISS), o estudo busca a caracterização os estabelecimentos de saúde em uma região piloto do Projeto QualiSUS-Rede, sob o olhar ascendente, integrado e regionalizado, identificando os serviços farmacêuticos voltados à qualificação da gestão da saúde no território e principalmente as atividades clínicas do farmacêutico. Neste sentido, o objetivo do estudo é caracterizar os estabelecimentos de saúde, com base nos serviços farmacêuticos, em ponto de atenção à saúde (PAS) e/ ou ponto de apoio terapêutico (PAT) da rede de atenção da $5^{\text {a }}$ região de saúde em Alagoas, por um estudo transversal de base censitária, com coleta de dados nas bases nacionais CNES e SIA, além de questionários para profissionais em serviço. Dos 143 estabelecimentos em atividade na região, 44\% foram caracterizados como PAT e $1 \%$ como PAS e PAT simultaneamente. O estudo demonstra a baixa oferta de serviços clínicos do farmacêutico e a fragilidade dos sistemas de informação voltados ao planejamento ascendente observando a necessidade dos usuários do Sistema Único de Saúde e que a caracterização proposta pode ser reproduzida em diferentes realidades regionais, inclusive apontando a necessidade de melhorias nos sistemas de informação e na qualificação da gestão do cuidado.

Palavras- chave: Assistência Farmacêutica, Cuidados Farmacêuticos, Planejamento em Saúde, Sistemas de Saúde, Saúde Coletiva. 


\begin{abstract}
From the perspective of pharmaceutical care and attempt to meet the recommendations for health planning in the SUS, within the guidelines for health services network and the guidelines of the World Health Organization (WHO) World Health Organization (WHO) for Integrated Health Service Delivery Networks (IHSDNs), the study seeks to characterize of health establishments in a pilot region QualiSUS-Rede Project, under the ascendant, integrated and regionalized look, identifying the pharmaceutical services for the qualification of health management in the territory and especially the clinical activities of the pharmacist. In this sense, the objective of the study is to characterize the health establishments based on pharmaceutical services, in point of health care (PHC) and therapeutic support or point (TPS) of the attention of the 5th region of Alagoas health network, crosssectional study based census that collected data in national databases CNES e SIA, and questionnaires to in-service professionals. Of the 143 establishments active in the region, 44\% were characterized as (TPS) and $1 \%$ as (PHC) and (TPS) simultaneously. The study demonstrates the low supply of clinical services of the pharmacist and the fragility of information systems aimed at ascending planning observing the need for users of the Unified Health System and that the proposed characterization can be reproduced in different regional realities, including pointing out the need for improvements in information systems and in the quality of care management
\end{abstract}

Key words: Pharmaceutical Services, Pharmaceutical Care, Health Planning, Health Systems, Public Health. 


\section{LISTA DE QUADROS}

Quadro 1 - Critérios para caraterização em ponto de atenção à saúde (PAS) e/ ou ponto de apoio terapêutico (PAT) dos estabelecimentos de saúde relacionados à assistência farmacêutica a partir da oferta de serviços

Artigo - A Assistência Farmacêutica nas Redes de Atenção à Saúde: o planejamento e os serviços no SUS

Quadro 1 - Critérios para caraterização em Ponto de Atenção à Saúde (PAS) e/ ou Ponto de Apoio Terapêutico (PAT) dos estabelecimentos de saúde relacionados à assistência farmacêutica a partir da oferta de serviços 


\section{LISTA DE FIGURAS}

Figura 1 - Exemplos de processos dos serviços farmacêuticos 


\section{LISTA DE TABELAS}

Artigo - A Assistência Farmacêutica nas Redes de Atenção à Saúde: o planejamento e os serviços no SUS

Tabela 1 - Caracterização dos estabelecimentos de saúde da $5^{\mathrm{a}} \mathrm{RS}$ segundo o tipo, serviços e informação de serviços de farmácia de acordo com Cadastro Nacional de Estabelecimentos de Saúde e Sistema de Informação Ambulatorial. Alagoas, Setembro 2013

Tabela 2 - Estabelecimentos de saúde da $5^{\mathrm{a}} \mathrm{RS}$ que atenderam os critérios de inclusão no estudo para Ponto de Atenção à Saúde (PAS) e Ponto de Apoio Terapêutico (PAT) segundo tipo, serviços especializados e informação de serviços de farmácia de acordo com 0 CNES. Setembro. 2013

Tabela 3 - Estabelecimentos de saúde da $5^{\text {a }}$ RS que atendem aos critérios de caracterização em Ponto de Atenção à Saúde (PAS), baseado nos serviços técnicos assistenciais de Clínica Farmacêutica. Alagoas, Setembro de 2013 


\section{LISTA DE ABREVIATURAS E SIGLAS}

AF - Assistência Farmacêutica

APS - Atenção Primária em Saúde

CAF - Centrais de Abastecimento Farmacêutico

CAPS - Centros de Atenção Psicossocial

CNES - Cadastro Nacional de Estabelecimentos de Saúde

CNS - Cartão Nacional de Saúde

CONEP - Comitê Nacional de Ética em Pesquisa

EUM - Estudos de Utilização de Medicamentos

HÓRUS - Sistema Nacional de Gestão da Assistência Farmacêutica

IBGE - Instituto Brasileiro de Geografia e Estatística

MS - Ministério da Saúde

NOAS - Norma Operacional de Assistência à Saúde

NOB - Norma Operacional Básica do SUS

OMS - Organização Mundial da Saúde

OPAS - Organização Pan-Americana de Saúde

Pacto pela Saúde - conjunto de reformas institucionais do SUS pactuado entre as três esferas de gestão - União, Estados e Municípios.

PAS - Ponto de Atenção à Saúde

PAT - Ponto de Apoio Terapêutico

PGASS - Programação Geral das Ações e Serviços de Saúde

PlanejaSUS - Sistema de Planejamento do SUS

QualiSUS-Rede - Projeto de Formação e Melhoria da Qualidade de Rede de Atenção à Saúde

RAS - Rede de Atenção à Saúde

RENASES - Relação Nacional de Ações e Serviços de Saúde

RISS - Redes Integradas de Serviços de Saúde

RS - Região de Saúde

RSB - Reforma Sanitária Brasileira

SAGE - Sala de Apoio à Gestão Estratégica

SCNES - Sistema de Cadastro Nacional de Estabelecimentos de Saúde

SIA - Sistema de Informações Ambulatoriais

SIA-SUS - Sistema de Informações Ambulatoriais do SUS 
SUS - Sistema Único de Saúde

TIC - Tecnológica da Informação e Comunicação UBS - Unidade Básica de Saúde 


\section{SUMÁRIO}

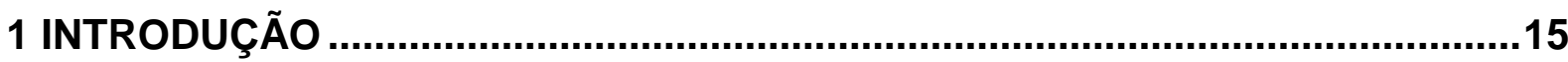

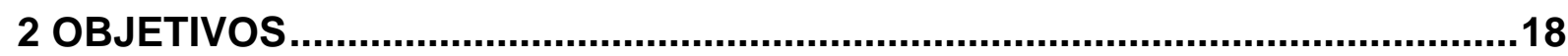

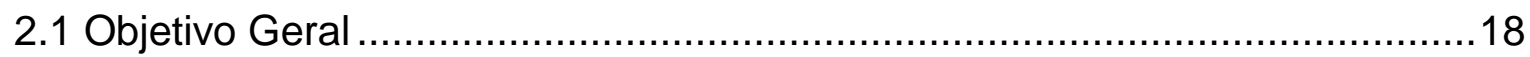

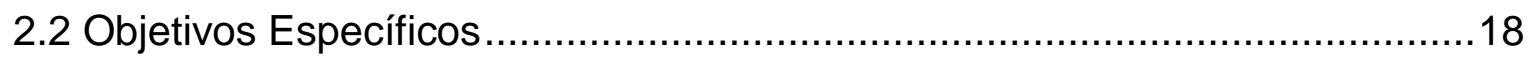

3 REFERENCIAL TEÓRICO

3.1 A Estratégia das Redes de Atenção à Saúde ............................................19

3.2 Serviços Farmacêuticos no SUS …………………………………….....22

3.3 Os Sistemas de Informações no SUS e a Assistência Farmacêutica .............25

3.4 O Projeto QualiSUS-Rede e a Assistência Farmacêutica ................................26

4 MÉTODOS

4.1 Delineamento do Estudo e Instrumentos de Coleta de Dados.......................28

4.2 A Estrutura Operacional da Região de Saúde e o Recorte do Estudo............28

4.3 Critério de Inclusão e Exclusão no Estudo...................................................29

4.4 A Coleta de Dados nas Bases Nacionais....................................................29

4.5 A Coleta de Dados nos Estabelecimentos de Saúde.....................................30

4.6 A Análise dos Dados para Ponto de Atenção e Ponto de Apoio Terapêutico 30

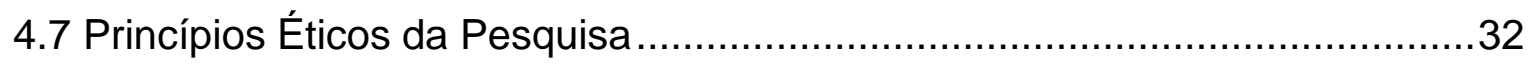

5 RESULTADOS E DISCUSSÃO

5.1 Artigo - A Assistência Farmacêutica nas Redes de Atenção à Saúde: o planejamento e os serviços no SUS ...............................................................33

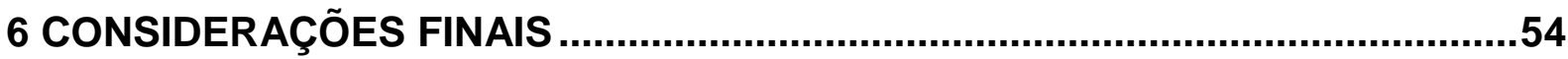

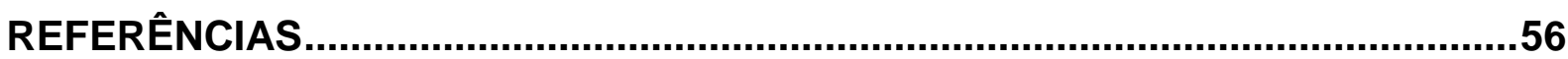

ANEXOS

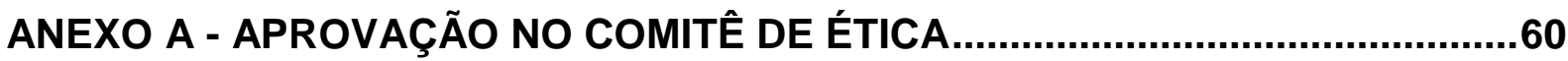

ANEXO B - QUESTIONÁRIO DE RESPONSÁVEL PELO PONTO DE ATENÇÃO E/

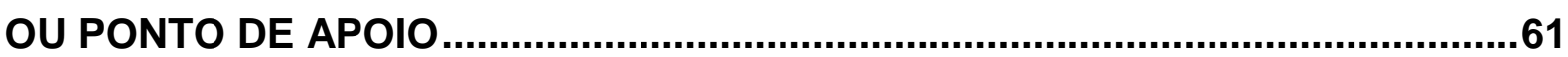
ANEXO C - COMPROVANTE DE SUBMISSÃO A REVISTA SAÚDE EM DEBATE 


\section{INTRODUÇÃO}

A Organização Pan-Americana de Saúde (OPAS) aponta que os sistemas de saúde das Américas são caracterizados por altos níveis de fragmentação. $\mathrm{Na}$ experiência de pessoas que utilizam o sistema, a fragmentação é expressa como a dificuldade de acesso a serviços, perda de continuidade de cuidados e a falta de coerência dos serviços com as necessidades do usuário. Apesar dos esforços dos países da região, o desafio de combater a fragmentação e prestar serviços contínuos de saúde mais justa e abrangente continua sendo um grande imperativo para a maioria dos países das Américas (OPAS, 2010).

Segundo Puig, et al. (2011), em estudo aplicando técnicas e instrumentos recomendados pela OPAS, identificou-se que apesar do sistema de saúde em Cuba, não permitir níveis de segmentação e fragmentação como nos demais sistemas de saúde na América Latina, a fragmentação se manifesta principalmente como problema de gestão para enfrentar os complexos problemas de saúde entre os diversos níveis e locais de atendimento do sistema cubano, mesmo que o país possua um modelo de atenção primária à saúde reconhecido como referência mundial.

Esse trabalho tende a se intensificar como aponta Mendes (2012), especialmente diante das mudanças demográficas evidenciadas pelo Brasil nas últimas décadas que refletiram diretamente no perfil epidemiológico nacional, que de forma singular, passou a conviver com a chamada tripla carga de doença, obrigando os gestores a buscar soluções assistenciais com especial atenção para o crescimento das causas externas e simultaneamente para as doenças crônicas, principalmente pelo significativo processo de envelhecimento da população, porém, tendo ainda que conviver com as doenças parasitárias, infecciosas e desnutrição, típicas dos países subdesenvolvidos.

No Brasil, os gestores de saúde, desde a criação do Sistema Único de Saúde (SUS), vêm pactuando normativas como NOB/93, NOB 01/96, NOAS 01 e 02/2003, PlanejaSUS e Pacto pela Saúde em 2006 no intuito de aproximar o que preconiza a política nacional de saúde com o planejamento em saúde, todas elas lançadas como estratégias para responder ao processo de descentralização e municipalização fortemente apontado desde a Reforma Sanitária Brasileira (RSB) e consolidado na 
constituição do país, na busca por um sistema de saúde com foco na regionalização e hierarquização da rede de serviços de saúde.

Em 2010, foram pactuadas as diretrizes para a estruturação da Rede de Atenção à Saúde (RAS) sendo definidas no Brasil como estratégia para superar a fragmentação da atenção e da gestão nas Regiões de Saúde, buscando aperfeiçoar o funcionamento político-institucional do Sistema Único de Saúde (SUS) com vistas a assegurar ao usuário o conjunto de ações e serviços que necessita, com efetividade e eficiência (BRASIL, 2010).

A estrutura operacional da RAS é constituída pelos diferentes pontos de atenção à saúde, ou seja, lugares institucionais onde se ofertam serviços de saúde e pelas ligações que os comunicam. Seus componentes incluem: APS - centro de comunicação; os pontos de atenção secundária e terciária; os sistemas de apoio; os sistemas logísticos e o sistema de governança. São exemplos de pontos de atenção à saúde: os domicílios, as unidades básicas de saúde, as unidades ambulatoriais especializadas, os serviços de hemoterapia e hematologia, os centros de apoio psicossocial, as residências terapêuticas, entre outros. Os hospitais podem abrigar distintos pontos de atenção à saúde: o ambulatório de pronto atendimento, a unidade de cirurgia ambulatorial, o centro cirúrgico, a maternidade, a unidade de terapia intensiva, a unidade de hospital/dia, entre outros (BRASIL, 2010).

Para Lavras (2011), entendem-se redes de atenção à saúde como arranjos organizativos de unidades funcionais de saúde, pontos de atenção e pontos de apoio diagnóstico e terapêutico, onde são desenvolvidos procedimentos de diferentes densidades tecnológicas que, integradas através de sistemas logísticos e de gestão, buscam garantir a integralidade do cuidado. Na ótica da OPAS (2010), considera-se que a RAS não é um trabalho acabado, mas um trabalho em andamento, a partir do qual a concretização do modelo proposto na prática dos serviços dependerá dos diferentes atores envolvidos.

No tocante as ações e serviços da Assistência Farmacêutica (AF) no país, o Ministério da Saúde destaca avanços nas pactuações envolvendo o planejamento, porém limitando-se a responsabilização dos entes, mas aponta que esses os esforços se voltaram para a aquisição e a distribuição de medicamentos, sem a preocupação com a organização dos serviços e sem planejamento, até mesmo para guiar a oferta de medicamentos à população. A reprodução desse modelo ao longo dos anos resultou na sua fragmentação, na baixa qualidade dos serviços 
farmacêuticos no SUS (tanto pela carência de recursos humanos qualificados quanto pelas questões de infra-estrutura), em menor eficiência e, conseqüentemente, em diminuição da capacidade de resolução dos problemas de saúde pelos serviços (BRASIL, 2006).

Nesse aspecto, pode-se citar as freqüentes perdas de medicamentos (por expiração de validade ou armazenamento inadequado), as trocas de medicamentos no momento da dispensação, a falta de orientação ao usuário sobre o uso dos medicamentos, o uso irracional, as faltas freqüentes de medicamentos essenciais no momento oportuno ao tratamento, entre tantos outros problemas (BRASIL, 2006).

Tavares et al. (2013), em estudo recente demonstrou que a frequência de doenças crônico-degenerativas que acomete os idosos e a predisposição à incapacidade funcional também são relevantes. Esses fatores devem ser considerados pelos profissionais de saúde na promoção da adesão ao tratamento e aumento da resolutividade terapêutica e da qualidade de vida desses pacientes. $O$ acompanhamento farmacoterapêutico dos idosos por parte dos serviços de saúde é fundamental, possibilitando a adoção de estratégias voltadas para as necessidades individuais específicas, focando a gestão compartilhada do tratamento entre profissionais e pacientes.

O modelo de atenção à saúde vigente, fundamentado nas ações curativas, centrado no cuidado médico e estruturado com ações e serviços de saúde dimensionados a partir da oferta, tem se mostrado insuficiente para superar os desafios sanitários atuais, e insustentável para os enfrentamentos futuros (BRASIL, 2010).

Segundo Araújo, et al. (2008), a atividade de orientação aos usuários na farmácia da unidade básica de saúde torna-se praticamente impossível, pois na farmácia deságuam quase todas as mazelas do sistema de saúde, por estar no elo final do processo de atendimento e em especial na atenção básica, o farmacêutico tem uma interação limitada com a equipe de saúde, por ter seu tempo preenchido na resolução de problemas operacionais com destaque para à gestão dos estoques. 


\section{OBJETIVOS}

\subsection{Objetivo Geral}

Caracterizar e analisar os estabelecimentos de saúde, enquanto ponto de atenção à saúde (PAS) e/ou ponto de apoio terapêutico (PAT), da 5a região de saúde em Alagoas de acordo com os serviços farmacêuticos ofertados à população.

\subsection{Objetivos Específicos}

- Identificar nas bases de dados nacional do Cadastro Nacional de Estabelecimentos de Saúde (CNES) e Sistema de Informação Ambulatorial (SIA) os estabelecimentos de saúde que apresentam serviços farmacêuticos e sua produção;

- Propor critérios para a inserção das atividades da assistência farmacêutica nas RAS nos pontos de atenção à saúde (PAS) e/ ou nos pontos de apoio terapêutico (PAT);

- Descrever os serviços farmacêuticos ofertados pelos profissionais farmacêuticos na região de saúde a partir da caracterização dos estabelecimentos em ponto de atenção à saúde e/ou ponto de apoio terapêutico na região;

- Analisar na perspectiva da assistência farmacêutica e seus serviços clínicos aspectos técnicos relevantes para consolidar o planejamento ascendente na rede regional de atenção à saúde analisando as informações disponíveis nas bases nacionais de dados (CNES e SIA). 


\section{REFERENCIAL TEÓRICO}

\subsection{A Estratégia das Redes de Atenção à Saúde}

Nas Américas, de acordo com OPAS/OMS (2013), existem várias experiências de boas práticas na criação de redes integradas de serviços, especialmente em países como Brasil, Canadá, Chile, Costa Rica e Cuba, que tradicionalmente apoiam o desenvolvimento de redes. Outros países da região estão adotando políticas semelhantes para organizar seus serviços de saúde. Apesar dos esforços envidados pelos países da região, o desafio de combater a fragmentação e prestar serviços contínuos de saúde de forma mais justa e abrangente continua sendo um grande imperativo para a maioria dos países da região.

A perspectiva de construção de sistemas integrados de serviços de saúde é favorecida pela utilização do conceito de redes de atenção à saúde, entendidas como potentes indutores da organização ou reorganização de sistemas locais e regionais. Essa abordagem implica uma atuação mais cooperativa entre as unidades de saúde, de modo a possibilitar a garantia do acesso e do atendimento integral à saúde dos usuários (LAVRAS, 2011)

No Brasil as políticas públicas voltadas ao setor saúde, focadas nas necessidades da população, sem dúvida vem inquietando gestores, pesquisadores, profissionais de saúde e principalmente usuários do SUS, em especial para que se predomine as decisões baseadas nos perfis epidemiológicos e nosológicos contemporâneos e se planeje a gestão e organização da rede a partir de ações e serviços de saúde pensados para atender a tripla carga de doenças, com maior investimento dos entes na estrutura regional e assim se garantir com qualidade e eficiência os serviços ao cidadão.

Ocorre que a situação de saúde brasileira vem mudando e, hoje, marca-se por uma transição demográfica acelerada e expressa-se por uma situação de tripla carga de doenças: uma agenda não superada de doenças infecciosas e carenciais, uma carga importante de causas externas e uma presença hegemônica forte de condições crônicas (MENDES, 2011).

Para Tanaka e Tamaki (2012), essa gestão de serviços de saúde constitui uma prática administrativa que tem a finalidade de otimizar o funcionamento das organizações de forma a obter o máximo de eficiência (relação entre produtos e 
recursos empregados), eficácia (atingir os objetivos estabelecidos) e efetividade (resolver os problemas identificados).

Na perspectiva de Cecílio e Mehry (2003), quando pensado, por exemplo, serviços hospitalares, o olhar sobre a chamada micropolítica do trabalho em saúde, nestes estabelecimentos deve buscar a modelagem da gestão como um todo a partir do cuidado do paciente. A própria lógica, em si, da produção do cuidado, e sua micropolítica, "transborda" o processo de coordenação e as atribuições de uma equipe assistencial, na medida em que só pode ser realizada de forma transversalizada, isto é, percorrendo várias unidades de cuidado do hospital. Mais do que isso, podemos dizer que, na perspectiva da integralidade, a transversalidade do cuidado realiza- se em uma rede mais ampla de serviços, na qual o hospital é apenas uma estação.

Percebesse que essas visões são complementares e demonstram o grau de complexidade da gestão em saúde e ao mesmo tempo os desafios para implementação de ações que envolvem desde a micropolítica nos estabelecimentos de saúde até a macro política e essas ações ao menos deveriam apontar no sentido da construção ascendente influenciando a tomada de decisão de gestores nos territórios e consequentemente no intuito de fortalecer a integração da rede regional de atenção à saúde.

Kuschnir e Chorny (2010) descrevem, do ponto de vista da gestão do sistema, que todos os serviços, tanto curativos como preventivos, estariam intimamente coordenados sob uma única autoridade de saúde para cada área. Sendo indispensável à unidade de ideias e propósitos, assim como a comunicação completa e recíproca entre os hospitais, os centros de saúde secundários e primários e os serviços domiciliares, independentemente de que os centros estejam situados no campo ou na cidade.

Nas últimas décadas uma das pautas principais das agendas dos gestores da saúde se concentra nas decisões voltadas a garantia integral dos serviços da assistência farmacêutica e a sua conformação na proposta apontada pela estratégia de Redes de Atenção à Saúde (RAS), na busca pela superação da fragmentação das ações e dos serviços de saúde e da gestão do cuidado, sendo ainda mais focada após a publicação do Decreto 7.508/2011, que regulamentou parte da Lei Orgânica da Saúde (8.080/1990), estabelecendo também como estratégia a elaboração nacional e regional de relações de medicamentos e de ações e serviços 
de saúde a serem ofertados pelo SUS.

O Ministério da Saúde (2012), ao entender que a assistência farmacêutica precisa ser inserida nas discussões relacionadas às Redes de Atenção à Saúde aponta para o desafio e descreve que a sua inserção e o desenvolvimento ainda se encontram em descompasso com relação ao conjunto de ações, serviços do SUS e das necessidades de saúde da população. As atividades de aquisição e distribuição consolidaram-se como foco e limite das atividades relacionadas aos medicamentos no país e para muitos, ela ainda é vista como um sistema logístico ou sistema de apoio, e ainda há aqueles que não consideram a AF como integrante do conjunto de ações e serviços do SUS, e enfocam o medicamento como mercadoria.

$\mathrm{Na}$ perspectiva da assistência farmacêutica e na tentativa de atender o preconizado para o planejamento em saúde no âmbito do SUS, observando as diretrizes pactuadas no país para as RAS e as orientações da Organização Mundial da Saúde (OMS) para as chamadas Redes Integradas de Serviços de Saúde (RISS), o presente estudo busca exercitar ou testar uma proposta de caracterização dos estabelecimentos de saúde em uma região piloto do Projeto QualiSUS-Rede, observando o caráter ascendente, integrado e regionalizado para se planejar, identificando no território os serviços farmacêuticos existentes voltados à qualificação da gestão e principalmente as atividades clínicas do farmacêutico.

Em sistemas públicos de saúde, segundo Lavras (2011), os territórios se constituem em espaços organizativos e de responsabilização sanitária e no Brasil, a União, os estados e os municípios são definidos previamente como territórios através de uma divisão político administrativa e, assim, já se constituem em territórios nos quais se organizam práticas sanitárias. Porém, na perspectiva de organização de redes de atenção à saúde, há que se configurar outros territórios que correspondem às regiões sanitárias.

Lavras (2011), ainda aponta que em processos de planejamento e/ou de reorganização de sistemas de saúde, a identificação das redes de serviços de saúde por nível hierárquico do sistema e de redes temáticas mostra-se necessária, por possibilitar uma melhor avaliação da oferta em função das necessidades de saúde existentes.

Essa organização do sistema de saúde, assim como demonstrado por Lavras (2011), Mendes $(2011$; 2012) e Silva, et al. (2013), precisa atender as diversas situações de modelagens e superar talvez o fator que mais interfere na conformação 
e consolidação das rede regionais de atenção à saúde, que é a fragmentação dos serviços e a ausência ou a frágil articulação existente entre, os seus diferentes pontos de atenção em seus diferentes níveis de atenção. Neste caso inclui-se os serviços farmacêuticos que também se apresentam fragilizados e normalmente afastados deste processo de construção da rede assistencial no território.

\subsection{Serviços Farmacêuticos no SUS}

Segundo o Ministério da Saúde (2012), a AF apresenta componentes de natureza técnica, científica, de inovação tecnológica e operativa, tendo por objeto a relação com o usuário, que devem ser ordenados de acordo com a complexidade, necessidades da população e finalidades dos serviços de saúde. A sua organização caracteriza-se como uma estratégia que procura superar a fragmentação entre seus componentes e a fragmentação mais ampla, ainda presente no SUS, caracterizando-se como um serviço de saúde.

As evidencias apontados por De Castro (2007), Vieira (2007) e Mendes (2012), demonstram que a implementação de serviços farmacêuticos que priorizem a necessidade de assistência desde a atenção básica até a atenção especializada ainda é desafiante, em especial quando a priorização das ações e serviços inerentes à assistência farmacêutica ainda está conformada e focada na lógica do acesso ao insumo chamado "medicamento". Isso prevalece não apenas na visão da gestão, mas também para o usuário e profissional farmacêutico que em virtude da sua formação mais tecnicista, na maioria das faculdades do país, focada na produção industrial e/ ou análises clínicas, precisa ser repensada, como resposta a mudança do perfil epidemiológico e nosológico da população, hoje caraterizado pela tripla carga de doenças e especialmente voltados para as doenças e condições crônicas.

Diante deste contexto e especialmente para a atenção básica, para a OPAS (2013) a prestação de serviços farmacêuticos se define como a chave, porque são eles que envolvem a relação direta com o usuário/ paciente. Fazem parte deste processo as atividades de promoção da saúde, de dispensação, acompanhamento/ seguimento farmacoterapêutico, farmacovigilância e apoio a automedicação responsável, entre outros. Apresentam-se também diferentes frente a diversidade de situações enfrentadas pelas pessoas, nas quais se faz necessário dar-lhes uma atenção especial, para que se ofertem serviços especialmente os clínicos. 
Neste sentido, os serviços farmacêuticos comporiam um conjunto de ações no sistema de saúde que busca garantir a atenção integral, integrada e continua as necessidades e problemas de saúde da população tanto individual como coletiva, tendo o medicamento como um dos elementos essenciais, e contribuindo para o acesso equitativo e uso racional. Essas ações, realizadas pelo farmacêutico ou sob sua coordenação incorporada a uma equipe de saúde e com a participação da comunidade, tem como objetivo alcançar resultados concretos de saúde com vistas melhora qualidade de vida da população (OPAS, 2013).

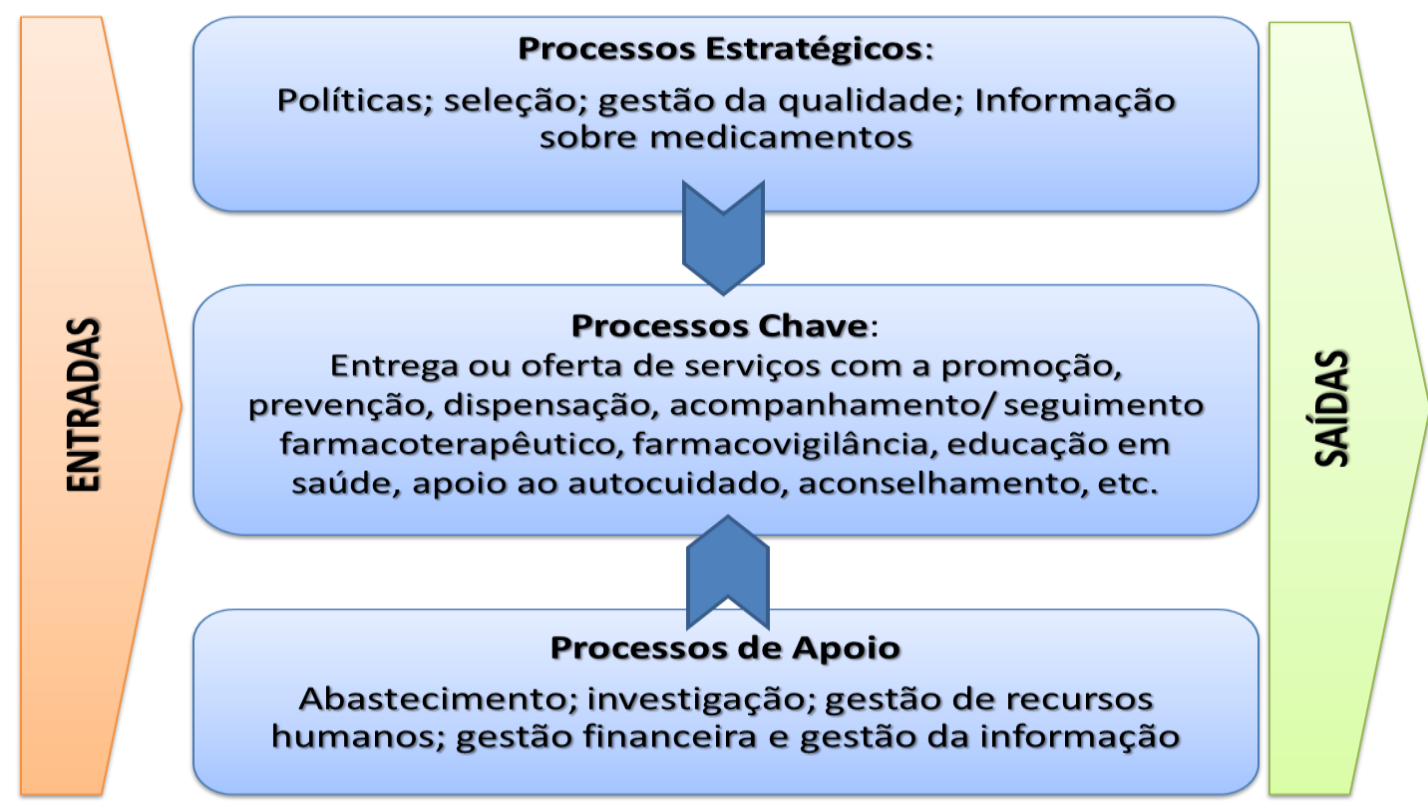

\section{Figura 1 - Exemplos de processos dos serviços farmacêuticos}

Fonte: OPAS (2013), Servicios farmacéuticos basados en la atención primaria de salud. Documento de posición de la OPS/OMS. Washington, DC : OPS, 2013.

Os serviços farmacêuticos no SUS têm a finalidade de propiciar o acesso qualificado aos medicamentos essenciais disponibilizados pela rede pública a seus usuários. (BRASIL, 2009).

O Ministério da Saúde (2009), ao descrever esses serviços farmacêuticos desenvolvidos nas farmácias, apontam os serviços técnico-gerenciais, que exigem profissionais capacitados para aplicar conhecimentos e informações epidemiológicas, administrativas e gerenciais para o planejamento e execução das ações, bem como os serviços técnico-assistenciais, neste caso é necessário uma equipe plenamente capacitada para aplicar conhecimentos sobre os medicamentos, a terapêutica, as habilidades e as competências para estabelecer a relação com os 
usuários dos serviços e a equipe de profissionais de saúde, ou seja, desenvolver o processo de gestão do cuidado no âmbito da farmácia.

No Brasil, segundo Vieira (2007), em meio a inúmeras necessidades e demandas, os serviços de farmácia no Brasil não são considerados prioritários na disputa por recursos nos orçamentos da saúde. Talvez a sua importância ainda não esteja explicitada para a maioria dos gestores. Isto é possível constatar pelas condições físicas e de recursos humanos em que se encontram, embora estudos sobre o tema sejam necessários.

No caso do SUS, o entrave para funcionar como uma rede é a pluralidade de formas jurídicas dos serviços de saúde, principalmente dos hospitais que prestam serviço para o SUS (privados, filantrópicos, empresas públicas, autarquias, organizações sociais e fundações estatais). Essa variedade tem imposto graus de compromisso e de integração extremamente heterogêneos dentro da rede assistencial, ocasionando, muitas vezes, situações de impermeabilidade explícita do serviço especializado diante das demandas da rede assistencial (BRASIL, 2012; CUNHA e CAMPOS, 2011).

Vieira (2007), ainda destaca a falta de pessoal qualificado não havendo assim condições apropriadas para que a AF desempenhe a sua função e para que de fato as relações sejam mais humanizadas e que zele pelo uso racional de medicamentos em parceria com os demais serviços e profissionais do sistema de saúde, o que se constitui um problema importante de saúde pública usando como comparação as informações que tratam da morbimortalidade relacionada a medicamentos nos Estados Unidos da América (EUA), país em que todas as farmácias possuem farmacêuticos, ou seja, muito diferente da realidade brasileira, em especial no setor público.

Mendes (2012) descreve ainda uma vasta literatura que ressalta a importância de atividades multiprofissionais desde os serviços prestados ao usuário na atenção básica, como no Brasil, por meio da Estratégia Saúde da Família, a ambulatórios de especialidades e serviços de alta complexidade que devem ser constituídos não apenas de profissionais médicos. Estes estudos apontam para a necessidade de serviços clínicos de farmacêuticos, enfermeiros, psicólogos, nutricionais, fisioterapeutas e outros, superando a medicina centrada na figura médica e ampliando a assistência, pensando a equipe de saúde de forma mais 
ampla e focada na elaboração da diretriz clínica com a participação ativa de todos esses profissionais.

\subsection{Os Sistemas de Informações no SUS e a Assistência Farmacêutica}

Outro aspecto importante para o planejamento em saúde e para a tomada de decisão dos gestores, além da definição dos serviços a serem ofertados em um território regional, está relacionado à estrutura de tecnologia da informação e comunicação disponível para monitorar, acompanhar e avaliar essa rede de atenção à saúde. Neste estudo e em especial para a caracterização proposta para os estabelecimentos de saúde com ações e serviços da assistência farmacêutica, alguns sistemas foram priorizados para as discussões iniciais de construção de parte do chamado mapa da saúde.

Na RAS os sistemas de informação são pensados para subsidiar a tomada de decisão do sistema de governança e desenhados segundo as necessidades de efetivação de um sistema eficaz de referência e contrarreferência de pessoas e de trocas eficientes de produtos e de informações ao longo dos pontos de atenção à saúde e dos sistemas de apoio na rede. Estão voltados para promover a integração dos pontos de atenção à saúde. Os principais sistemas logísticos da rede de atenção à saúde são: os sistemas de identificação e acompanhamento dos usuários; as centrais de regulação, registro eletrônico em saúde e os sistemas de transportes sanitários (BRASIL, 2010).

Para a assistência farmacêutica que se encontra na organização ou estrutura operacional da RAS como sistema de apoio, cabe ressaltar que este se conforma desta maneira sem que o papel assistencial, ou seja, os serviços de cuidados farmacêuticos tenham sido bem definidos, porém também estão fortemente ancorados na utilização de tecnologia da informação e comunicação (TIC) na rede regional.

A garantia de uma informação de qualidade é condição essencial para a análise objetiva da situação sanitária, para a tomada de decisões baseadas em evidências e para a programação de ações de saúde (COSTA, 2012; LIMA, 2009)

Foi por meio do Sistema Hórus que a assistência farmacêutica começou a se enxergar a estrutura territorial, uma vez que sua construção permeou a integração com outras bases de dados de outros sistemas, especialmente o Cartão Nacional de 
Saúde (CNS) e o Cadastro Nacional de Estabelecimentos de Saúde (CNES), entre outros, porém para a conformação da rede e do exercício inicial de um mapa que apresente um diagnóstico do território, o cadastro de estabelecimentos de saúde com seus respectivos serviços descritos, atrelados aos sistemas de produção ambulatoriais e hospitalares acabam sendo prioritários nas definições de estruturas e potencialidades em todos os níveis de governo e de gestão (COSTA, 2012).

É sob essa perspectiva que a construção de instrumentos tecnológicos voltados ao setor saúde precisa ser pensada, a exemplo do ocorrido com a criação e implementação do Sistema Nacional de Gestão da Assistência Farmacêutica Hórus, que surge para possibilitar maior segurança no acesso e utilização do medicamento ao usuário e o seu aprimoramento contínuo e a integração com os demais sistemas de informação em saúde permitirá que essas informações estejam contempladas no Registro Eletrônico de Saúde que se encontra em desenvolvimento no Brasil (COSTA, 2012).

Neste sentido, o planejamento para a AF necessariamente precisa ser concebido observando as tecnologias da informação disponíveis, para entender inicialmente se estas atendem a esta demanda de diagnóstico, no tocante a entrada e saída de dados confiáveis e atualizados, bem como se estes precisam ser utilizados da melhor forma possível ou até mesmo aprimorados ou substituídos enquanto ferramentas tecnológicas voltadas à tomada de decisão, sendo esta uma das perspectivas de avaliação do presente estudo que precisará caracterizar os estabelecimentos de saúde da $5^{\text {a }}$ RS a partir do CNES e SIA, observando a estrutura informada pelos entes federados e a produção especificamente de caráter clínico do farmacêutico.

\subsection{O Projeto QualiSUS-Rede e a Assistência Farmacêutica}

O Projeto de Formação e Melhoria da Qualidade de Rede Atenção à Saúde (QualiSUS-Rede) é uma proposta de intervenção para apoiar a organização de redes regionalizadas de atenção à saúde no Brasil. Trata-se de um projeto de cooperação entre o Banco Mundial e o Ministério da Saúde que visa somar-se aos esforços permanentes de consolidação do Sistema Único de Saúde - SUS, contribuindo para a melhoria da qualidade da atenção e da gestão através do desenvolvimento de tecnologias e do apoio à organização das RAS e melhorando a 
capacidade do sistema para responder aos atuais desafios sanitários com cenário de crescimento e prevalência das condições crônicas de saúde (BRASIL, 2011).

A pesquisa conduzida pelo Ministério da Saúde por meio do Projeto QualiSUS-Rede visa caracterizar a assistência farmacêutica nas 15 Regiões prioritárias do projeto, que envolvem 485 municípios e o Distrito Federal onde se busca apoiar as redes de atenção à a saúde. Utilizando inicialmente cinco instrumentos de coleta de dados definidos para aplicação a profissionais de saúde nas regiões, denominados: Secretário de Saúde, o Responsável pela assistência farmacêutica, o Responsável pela farmácia hospitalar e o de Responsável pelo ponto de atenção e/ ou ponto de apoio terapêutico e um quinto denominado Responsável pela central de abastecimento farmacêutico.

Estes instrumentos de coleta de dados foram elaborados na perspectiva de quatro dimensões que envolvem a AF sendo elas: Dimensão D1. Gestão para desenvolvimento da Assistência Farmacêutica; Dimensão D2. Estrutura e condições de funcionamento da Assistência Farmacêutica; Dimensão D3. Acesso e qualidade da atenção Dimensão D4. Financiamento.

Os instrumentos estão sendo aplicados nos municípios apoiados pelos 15 subprojetos do QualiSUS-Rede, em todos os pontos de apoio terapêutico e pontos de atenção, relacionados aos serviços farmacêuticos, quais sejam: Centrais de Abastecimento Farmacêuticos (municipais e/ou estaduais), Centros de Atenção Psicossocial (CAPS), farmácias (com dispensação de medicamentos dos componente básico, estratégico ou especializado), farmácias populares do Brasil e hospitalares da rede própria existentes nas regiões com base nas informações da Sala de Apoio à Gestão Estratégica (SAGE), Censo de Unidades Básica de Saúde e Cadastro Nacional de Estabelecimentos de Saúde (CNES) (BRASIL, 2013). 


\section{MÉTODOS}

\subsection{Delineamento do Estudo e Instrumentos de Coleta de Dados}

Trata-se de um estudo transversal, de aspecto censitário, realizado no segundo semestre de 2013, que incluiu os estabelecimentos de saúde de todos os municípios da $5^{\underline{a}} \mathrm{RS}$ em Alagoas, sendo a coleta e o tratamento de dados realizados por profissionais farmacêuticos devidamente treinados.

Para o presente estudo foi considerado um recorte dos resultados do questionário do Responsável pelo Ponto de Atenção e/ou Apoio Terapêutico (ANEXO B) que foi aplicado a profissionais responsáveis nos estabelecimentos de saúde pela área ou setor de farmácia, buscando coletar dados para caracterizar o estabelecimento em ponto(s) de atenção à saúde e/ ou ponto(s) de apoio terapêutico, excluindo-se destes os estabelecimentos de atenção pré-hospitalares de urgência e os hospitalares, bem como as centrais de abastecimento farmacêutico (CAF) que não entregavam e/ ou dispensavam medicamentos.

Para a caracterização de serviços farmacêuticos no âmbito do SUS, baseado nas diretrizes propostas para as redes de atenção à saúde e frente aos referenciais teóricos desta pesquisa, propõe-se duas definições a partir dos serviços ofertados na Assistência Farmacêutica, sendo elas a do Ponto de Atenção à Saúde (PAS) e do Ponto de Apoio Terapêutico (PAT).

\subsection{A Estrutura Operacional da Região de Saúde e o Recorte do Estudo}

A 5ạ Região de Saúde é constituída por sete municípios: Anadia, Boca da Mata, Campo Alegre, Junqueiro, Roteiro, São Miguel dos Campos e Teotônio Vilela, que juntos totalizam uma população de 234.815 segundo estimativa do IBGE 2013.

O presente estudo é um recorte dos dados obtidos do questionário respondido pelo Responsável pelo Ponto de Atenção e/ou Apoio Terapêutico (ANEXO B) aplicado na região piloto, para validação dos instrumentos da pesquisa do Projeto QualiSUS-Rede.

Foram utilizados para complementar a caracterização e a identificação dos estabelecimentos de saúde, dados secundários disponibilizados em setembro de 2013 pelo Ministério da Saúde por meio do Cadastro Nacional de Estabelecimentos 
de Saúde (CNES) e dos serviços e procedimentos constantes do Sistema de Informações Ambulatoriais (SIA).

Os dados obtidos do CNES apresentaram um total de 156 estabelecimentos nos municípios da $5^{\mathrm{a}}$ RS até setembro de 2013 e a presença de 11 farmacêuticos, vinculados no mínimo a um estabelecimento de saúde cada, desenvolvendo suas funções com carga horária mínima de 20 horas semanais (BRASIL, 2013b).

\subsection{Critério de Inclusão e Exclusão no Estudo}

Observando-se o piloto do Projeto QualiSUS-Rede (2013) incluiu-se, inicialmente, como unidade de análise os estabelecimentos de saúde da região que realizavam entrega e/ ou dispensação de medicamentos, tais como Unidades Básicas de Saúde, Centrais de Abastecimento Farmacêuticos (municipais e/ou estaduais e federais), Centros de Atenção Psicossocial (CAPS), farmácias (com entrega e ou dispensação de medicamentos do componente básico, estratégico e/ou especializado), farmácias populares do Brasil (Rede Própria), e outros estabelecimentos de média e alta complexidade da rede própria da região e/ ou unidades de saúde prestadoras de serviços ao SUS.

Foram excluídas as Centrais de Abastecimento Farmacêuticos que não realizavam entrega e/ ou dispensação de medicamentos e os estabelecimentos hospitalares.

\subsection{A Coleta de Dados nas Bases Nacionais}

A identificação dos estabelecimentos de saúde da região foi realizada inicialmente na base de dados nacional do CNES, verificando as informações de cada um dos códigos dos estabelecimentos, identificando a existência de cadastros ativos e serviços farmacêuticos registrados.

No intuito de identificar por município da região os locais de entrega e/ ou dispensação de medicamentos e quantificá-los, utilizou-se, de acordo com o preconizado para o Cadastro Nacional de Estabelecimentos de Saúde (CNES), o tipo de estabelecimento com o código 43 para Farmácia em edificação exclusiva, em seguida foi identificado os serviços especializados com código 125 para Serviço de Farmácia e suas classificações de 01 a 07 e por fim os serviços de apoio com código 03 de Farmácia, este último sendo utilizado para 
estabelecimentos de saúde que informavam dispor deste setor como serviço de apoio.

Uma vez realizada a identificação dos estabelecimentos da região de saúde para aplicação dos instrumentos do estudo verificou-se no CNES as informações de cada um dos códigos para identificar se existiam cadastrados de serviços farmacêuticos que caracterizassem os locais de entrega e/ ou dispensação de medicamentos aos usuários no território. De forma complementar também foi consultado o SIA para observar a existência de produção de serviços por profissionais de saúde, não médicos, em especial que caracterizassem atividades clínicas dos profissionais farmacêuticos.

As informações obtidas por meio das bases de dados oficiais do país, CNES e SIA, foram utilizadas para confrontar com as informações coletas nos municípios durante aplicação do questionário no intuito de identificar a realização, em especial dos serviços clínicos desenvolvidos por farmacêuticos.

No primeiro contato no território, o secretário municipal de saúde e/ ou o responsável pela assistência farmacêutica, apontavam para o entrevistador, os estabelecimentos de saúde que realizavam entrega e/ ou dispensação dos medicamentos para que em seguida ocorresse à aplicação do questionário para o profissional entrevistado nos estabelecimentos identificado como farmácia de edificação exclusiva ou como um dos setores do referido estabelecimento.

\subsection{A Coleta de Dados nos Estabelecimentos de Saúde}

O profissional de saúde responsável pelo serviço de farmácia foi identificado no estabelecimento, sendo convidado a participar da pesquisa e em seguida aplicouse o questionário complementado pelo preenchimento da observação direta do entrevistador (BRASIL, 2013).

\subsection{A Análise dos Dados para Ponto de Atenção e Ponto de Apoio Terapêutico}

Para a análise descritiva exploratória das variáveis ou critérios envolvidos no estudo foi utilizado o programa estatístico IBM SPSS Statistics 20.

Foi realizado um recorte do questionário que definia as variáveis que envolviam serviços clínicos para caracterizar as ações e serviços de saúde do estabelecimento ou serviço "farmácia" enquanto ponto de atenção à saúde e/ ou ponto de apoio terapêutico (Quadro 1). 
$\mathrm{Na}$ caracterização do Ponto de Atenção á Saúde (PAS) foi considerado quando o estabelecimento e respectivo setor ou área identificado, tem profissional farmacêutico (responsável técnico e/ou assistente) e realiza pelo menos um dos serviços clínicos. Na assistência farmacêutica estes serviços de produção singular, para fins deste estudo, foram entendidos como atividades de clínica farmacêutica, que seriam categorizados como serviços técnicos assistenciais, ou seja, serviços clínicos tais como Dispensação, Orientação Terapêutica/ Saúde, Seguimento Farmacoterapêutico e Conciliação de Medicamentos.

Para caracterização do Ponto de Apoio Terapêutico (PAT) foi considerado quando o profissional do estabelecimento e respectivo setor ou área identificado, referiu ofertar no mínimo um serviço ou atividade de apoio à rede regional, sendo estes relacionados à Seleção, Programação, Aquisição, Armazenagem e Distribuição de Medicamentos, a Farmacovigilância e Estudos de Utilização de Medicamentos (EUM), a Entrega de Medicamentos ao usuário, que para o estudo, corresponde ao fornecimento de medicamentos por profissional, inclusive farmacêutico, nos estabelecimentos de saúde, mediante apresentação de prescrição, seja em receituário específico ou por meio de registro em prontuário, sem que se realizem serviços clínicos farmacêuticos inerentes ao ponto de atenção.

Para a caracterização do PAT considerou-se quando o estabelecimento ofertava pelo menos um dos serviços farmacêuticos gerenciais na forma de apoio para os demais pontos de atenção da RAS.

Quadro 1 - Critérios para caraterização em ponto de atenção à saúde (PAS) e/ ou ponto de apoio terapêutico (PAT) dos estabelecimentos de saúde relacionados à assistência farmacêutica a partir da oferta de serviços

\begin{tabular}{l|l}
\hline \multicolumn{1}{c|}{$\begin{array}{c}\text { Ponto de Atenção à Saúde (PAS) } \\
\text { (Serviços Técnicos Assistenciais de Clínica } \\
\text { Farmacêutica) }\end{array}$} & \multicolumn{1}{c}{$\begin{array}{l}\text { Ponto de Apoio Terapêutico (PAT) } \\
\text { (Serviços Técnicos Gerenciais de Apoio a RAS) }\end{array}$} \\
\hline $\begin{array}{l}\text { Dispensação de Medicamentos } \\
\text { Orientação Terapêutica } \\
\text { Seguimento Farmacoterapêutico } \\
\text { Conciliação Terapêutica } \\
\text { Revisão da Farmacoterapia }\end{array}$ & $\begin{array}{l}\text { Seleção de Medicamentos } \\
\text { Programação de Medicamentos } \\
\text { Aquisição de Medicamentos } \\
\text { Armazenagem de Medicamentos } \\
\text { Distribuição de Medicamentos } \\
\text { Farmacovigilância e Estudo de Utilização } \\
\text { Medicamentos (EUM) } \\
\text { Entrega de medicamentos }\end{array}$ \\
\hline
\end{tabular}




\section{Conclusão}

Fonte: Elaborado pelo autor com base com base na Portaria MS no 4.279 (Brasil, 2010) e Documento Técnico do Ministério da Saúde denominado "A assistência farmacêutica nas Redes de Atenção à Saúde no SUS”. (Brasil, 2012).

\subsection{Princípios Éticos da Pesquisa}

Os instrumentos, dados coletados e resultados deste estudo são parte do projeto de pesquisa denominado 'A Assistência Farmacêutica nas Redes de Atenção à Saúde: Um Recorte nas Regiões do Projeto QualiSUS-Rede', aprovado pelo Comitê Nacional de Ética em Pesquisa (CONEP), processo CAAE 19554413.6.0000.0008, tendo como fonte financiadora o Ministério da Saúde, sendo portanto, os princípios éticos assegurados. 


\section{RESULTADOS E DISCUSSÃO}

\subsection{Artigo - A Assistência Farmacêutica nas Redes de Atenção à Saúde: o planejamento e os serviços no SUS}

Artigo em análise, submetido em 22/08/2014 e inserido na dissertação em formato padrão da Revista Saúde em Debate (ANEXO C).

Tipo: Artigo Original.

\section{A Assistência Farmacêutica nas Redes de Atenção à Saúde: o planejamento e os serviços no SUS}

The Pharmaceutical Services Networks in Health Care: planning and services in SUS

Suetônio Queiroz de Araújoํ, Rafael Mota Pinheiro², Noemia Urruth Leão Tavares ${ }^{3}$

\section{RESUMO}

O estudo objetiva caracterizar os estabelecimentos de saúde, com base nos serviços farmacêuticos, em ponto de atenção à saúde (PAS) e/ ou ponto de apoio terapêutico (PAT) da rede de atenção da $5^{\underline{a}}$ região de saúde em Alagoas, por estudo transversal de base censitária, com coleta de dados nas bases nacionais $e$ questionários para profissionais em serviço. Dos 143 estabelecimentos em atividade na região, 44\% foram caracterizados como PAT e 1\% como PAS e PAT simultaneamente. O estudo demonstra a baixa oferta de serviços clínicos do farmacêutico e a fragilidade dos sistemas de informação voltados ao planejamento ascendente observando a necessidade dos usuários do Sistema Único de Saúde.

Palavra- chave: Assistência Farmacêutica, Cuidados Farmacêuticos, Planejamento em Saúde, Sistemas de Saúde, Saúde Coletiva.

\section{ABSTRACT}

The study aims to characterize the health facilities based on pharmaceutical services, in point of health care (PHC) and therapeutic support or point (TPS) of the attention of the 5th region of Alagoas health network, cross-sectional study based census that collected data in national databases and structured interviews to inservice professionals. Of the 143 establishments active in the region, 44\% were characterized as (TPS) and 1\% as (PHC) and (TPS) simultaneously. The study demonstrates the low supply of clinical services of the pharmacist and the fragility of 
information systems aimed at ascending planning observing the need for users of the Unified Health System.

Key words: Pharmaceutical Services, Pharmaceutical Care, Health Planning, Health Systems, Public Health.

1.Mestrando em Saúde Coletiva. Universidade de Brasília. Programa de Pós Graduação em Saúde Coletiva. Tel. (82) 9976.9354. Endereço eletrônico: suetonioqueiroz@gmail.com

2.Doutor em medicina ciências médicas. UFRGS. Universidade de Brasília. Programa de Pós Graduação em Saúde Coletiva. Faculdade Ciências da Saúde. Campus Darcy Ribeiro. Brasília. DF. 61. 31071952. Endereço eletrônico: pinheirorafael@yahoo.com

3.Doutora em epidemiologia. UFRGS. Universidade de Brasília. Programa de Pós Graduação em Saúde Coletiva. Faculdade Ciências da Saúde. Campus Darcy Ribeiro. Brasília. DF. 61.31071952. Endereço eletrônico: nul.tavares@gmail.com

"Declaro que não houve conflito de interesses na concepção deste trabalho"

\section{INTRODUÇÃO}

A Organização Pan-Americana de Saúde (OPAS) aponta que os sistemas de saúde das Américas são caracterizados por altos níveis de fragmentação dos serviços de saúde. Na experiência de pessoas que utilizam o sistema, a fragmentação é expressa como a falta de acesso a serviços, perda de continuidade de cuidados e a falta de coerência dos serviços com as necessidades do usuário. Apesar dos esforços dos países da região, o desafio de combater a fragmentação e prestar serviços contínuos de saúde mais justa e abrangente continua sendo um grande imperativo para a maioria dos países das Américas (OPAS, 2010).

Segundo Puig, et al. (2011), em estudo aplicando técnicas e instrumentos recomendados pela OPAS, identificou-se que apesar do sistema de saúde em Cuba, não permitir níveis de segmentação e fragmentação como nos sistemas de saúde na América Latina, a fragmentação se manifesta principalmente como problema de gestão frente aos complexos problemas de saúde entre os diversos níveis e locais de atendimento do sistema cubano, mesmo que o país possua um modelo de atenção primária à saúde reconhecido como referência mundial.

No Brasil, os gestores de saúde, desde a criação do Sistema Único de Saúde (SUS), vêm pactuando normativas como NOB/93, NOB 01/96, NOAS 01 e 02/2003, PlanejaSUS e Pacto pela Saúde em 2006 no intuito de aproximar o que preconiza a política nacional de saúde com o planejamento em saúde, todas elas lançadas como 
estratégias para responder ao processo de descentralização e municipalização fortemente apontado desde a Reforma Sanitária Brasileira (RSB) e consolidado na constituição do país, na busca por um sistema de saúde com foco na regionalização e hierarquização da rede de serviços de saúde.

Em 2010, foram pactuadas as diretrizes para a estruturação da Rede de Atenção à Saúde (RAS) sendo definidas no Brasil como estratégia para superar a fragmentação da atenção e da gestão nas Regiões de Saúde, buscando aperfeiçoar o funcionamento político-institucional do Sistema Único de Saúde (SUS) com vistas a assegurar ao usuário o conjunto de ações e serviços que necessita, com efetividade e eficiência (BRASIL, 2010).

A estrutura operacional da RAS é constituída pelos diferentes pontos de atenção à saúde, ou seja, lugares institucionais onde se ofertam serviços de saúde e pelas ligações que os comunicam. Seus componentes incluem: APS - centro de comunicação; os pontos de atenção secundária e terciária; os sistemas de apoio; os sistemas logísticos e o sistema de governança. São exemplos de pontos de atenção à saúde: os domicílios, as unidades básicas de saúde, as unidades ambulatoriais especializadas, os serviços de hemoterapia e hematologia, os centros de apoio psicossocial, as residências terapêuticas, entre outros. Os hospitais podem abrigar distintos pontos de atenção à saúde: o ambulatório de pronto atendimento, a unidade de cirurgia ambulatorial, o centro cirúrgico, a maternidade, a unidade de terapia intensiva, a unidade de hospital/dia, entre outros (BRASIL, 2010).

Ainda sob a ótica da OPAS (2010), considera-se que a RAS não é um trabalho acabado, mas um trabalho em andamento, a partir do qual a concretização do modelo proposto na prática do sistema e dos serviços dependerá dos diferentes atores envolvidos.

Esse trabalho tende a se intensificar como aponta Mendes (2012), especialmente diante das mudanças demográficas evidenciadas pelo Brasil nas últimas décadas que refletiram diretamente no perfil epidemiológico nacional, que de forma singular, passou a conviver com a chamada tripla carga de doença, obrigando os gestores a buscar soluções assistenciais com especial atenção para o crescimento das causas externas e simultaneamente para as doenças crônicas, principalmente pelo significativo processo de envelhecimento da população, porém, tendo ainda que conviver com as doenças parasitárias, infecciosas e desnutrição, típicas dos países subdesenvolvidos. 
No tocante as ações e serviços da Assistência Farmacêutica (AF) no país, o Ministério da Saúde destaca avanços nas pactuações envolvendo o planejamento, porém limitando-se a responsabilização dos entes, mas aponta que esses esforços se voltaram para a aquisição e a distribuição de medicamentos, sem a preocupação com a organização dos serviços e sem planejamento, até mesmo para guiar a oferta de medicamentos à população. A reprodução desse modelo ao longo dos anos resultou na sua fragmentação, na baixa qualidade dos serviços farmacêuticos no SUS (tanto pela carência de recursos humanos qualificados quanto pelas questões de infra-estrutura), em menor eficiência e, conseqüentemente, em diminuição da capacidade de resolução dos problemas de saúde pelos serviços (BRASIL, 2006).

Nesse aspecto, pode-se citar as freqüentes perdas de medicamentos (por expiração de validade ou armazenamento inadequado), as trocas de medicamentos no momento da dispensação, a falta de orientação ao usuário sobre o uso dos medicamentos, o uso irracional, as faltas freqüentes de medicamentos essenciais no momento oportuno ao tratamento, entre tantos outros problemas (BRASIL, 2006).

Tavares et al.(2013), em estudo recente demonstrou que a frequência de doenças crônico-degenerativas que acomete os idosos e a predisposição à incapacidade funcional também são relevantes esses fatores devem ser considerados pelos profissionais de saúde para promoção da adesão ao tratamento e aumento da resolutividade terapêutica e da qualidade de vida desses pacientes. $O$ acompanhamento farmacoterapêutico dos idosos por parte dos serviços de saúde é fundamental, possibilitando a adoção de estratégias voltadas para as necessidades individuais específicas, focando a gestão compartilhada do tratamento entre profissionais e pacientes.

O modelo de atenção à saúde vigente, fundamentado nas ações curativas, centrado no cuidado médico e estruturado com ações e serviços de saúde dimensionados a partir da oferta, tem se mostrado insuficiente para superar os desafios sanitários atuais, e insustentável para os enfrentamentos futuros (BRASIL, 2010).

Segundo Araújo, et al. (2008), em especial na atenção básica, o farmacêutico tem uma interação limitada com a equipe de saúde, por ter seu tempo preenchido através da resolução de problemas operacionais referentes à gestão dos estoques e atendimento aos usuários. 
Neste contexto e na perspectiva de rediscussão e redesenho das ações e serviços de saúde, tendo entre suas prioridades a assistência farmacêutica como fator indissociável para a melhoria da assistência à saúde do cidadão, o presente estudo tem o objetivo de caracterizar os serviços farmacêuticos prestados aos usuários do SUS, enquanto ponto de atenção e ou ponto de apoio terapêutico, sob a ótica das redes de atenção à saúde, articulada ao processo de planejamento em saúde em uma Região de Saúde (RS) no Estado de Alagoas.

\section{MÉTODO}

O estudo foi realizado na 5a Região de Saúde de Alagoas, sendo um recorte do piloto para validação dos instrumentos, do Projeto QualiSUS-Rede do Ministério da Saúde que instituiu como estratégia para apoio à organização das RAS em 15 regiões de saúde do país a qualificação da gestão da assistência farmacêutica.

Foram utilizados para identificação dos estabelecimentos de saúde dados secundários disponibilizados, em setembro de 2013, pelo Ministério da Saúde por meio do sistema de Cadastro Nacional de Estabelecimentos de Saúde (CNES) e dos serviços e procedimentos constantes do Sistema de Informações Ambulatoriais (SIA).

\section{A estrutura operacional da Região de Saúde e o recorte do estudo}

A 5 $5^{\text {a }}$ Região de Saúde é constituída por sete municípios: Anadia, Boca da Mata, Campo Alegre, Junqueiro, Roteiro, São Miguel dos Campos e Teotônio Vilela, que juntos totalizam uma população de 234.815 segundo estimativa do IBGE 2013.

Os dados obtidos do Cadastro Nacional de Estabelecimentos de Saúde (CNES) apresentaram um total de 156 estabelecimentos nos municípios da $5^{\mathrm{a}} \mathrm{RS}$ até setembro de 2013 e possuíam em seus quadros de profissionais, 11 farmacêuticos, vinculados no mínimo a um estabelecimento de saúde cada, desenvolvendo suas funções com carga horária mínima de 20 horas semanais (BRASIL, 2013b).

Para a região e observando o piloto do Projeto QualiSUS-Rede (2013) incluiu-se, inicialmente, como unidade de análise os estabelecimentos de saúde da região que realizavam 'entrega e/ ou dispensação de medicamentos', tais como Unidades Básicas de Saúde, Centrais de Abastecimento Farmacêuticos (municipais e/ou estaduais e federais que realizem entrega e/ ou dispensação de 
medicamentos), Centros de Atenção Psicossocial (CAPS), farmácias (com entrega e/ ou dispensação de medicamentos do componente básico, estratégico e/ou especializado), farmácias populares do Brasil (Rede Própria), estabelecimentos de média e alta complexidade da rede própria da região e/ ou unidades de saúde prestadoras de serviços ao SUS.

\section{Delineamento do estudo e instrumentos de coleta de dados}

Trata-se de um estudo transversal, de aspecto censitário, realizado no segundo semestre de 2013, que incluiu os estabelecimentos de saúde de todos os municípios da $5^{\text {a }} \mathrm{RS}$ em Alagoas, sendo a coleta e o tratamento de dados realizados por profissionais farmacêuticos devidamente treinados.

Para o presente estudo foi considerado um recorte dos resultados do questionário do 'Responsável pelo Ponto de Atenção e/ou Apoio Terapêutico' destinado a entrevistas de profissionais responsáveis nos estabelecimentos de saúde pela área ou setor de farmácia, buscando coletar dados para caracterizar o estabelecimento em ponto(s) de atenção à saúde e/ ou ponto(s) de apoio terapêutico, excluindo-se destes os estabelecimentos de atenção pré-hospitalares de urgência e os hospitalares, bem como as centrais de abastecimento farmacêutico (CAF) que não entregavam e/ ou dispensavam medicamentos.

Para a caracterização de serviços farmacêuticos no âmbito do SUS, baseado nas diretrizes propostas para as redes de atenção à saúde e frente aos referenciais teóricos desta pesquisa, propõe-se duas definições para sua caracterização a partir dos serviços ofertados na Assistência Farmacêutica, sendo elas a do Ponto de Atenção à Saúde (PAS) e do Ponto de Apoio Terapêutico (PAT).

\section{A coleta de dados nas bases de dados nacionais}

A identificação dos estabelecimentos de saúde da região foi realizada inicialmente na base de dados nacional do CNES, verificando as informações de cada um dos códigos dos estabelecimentos, identificando a existência de cadastros ativos e serviços farmacêuticos registrados.

No intuito de identificar por município da região os locais de 'entrega e/ ou dispensação de medicamentos' e quantificá-los, utilizou-se, de acordo com o preconizado para o Cadastro Nacional de Estabelecimentos de Saúde (CNES), o 'tipo de estabelecimento' com o código 43 para Farmácia em edificação exclusiva, em seguida foi identificado os 'serviços especializados' com código 125 para Serviço de Farmácia e suas classificações de 01 a 07 e por fim os 'serviços de 
apoio' com código 03 de Farmácia, este último sendo utilizado para estabelecimentos de saúde que informavam dispor deste setor como serviço de apoio.

Uma vez realizada a identificação dos estabelecimentos da região de saúde para aplicação dos instrumentos do estudo verificou-se no CNES as informações de cada um dos códigos para identificar se existiam cadastrados de serviços farmacêuticos que caracterizassem os locais de entrega e/ ou dispensação de medicamentos aos usuários no território. De forma complementar também foi consultado o SIA-SUS para observar a existência de produção de serviços por profissionais de saúde, não médicos, em especial que caracterizassem atividades clínicas dos profissionais farmacêuticos.

As informações obtidas por meio das bases de dados oficiais do país, CNES e SIA, foram utilizadas para confrontar com as informações coletas nos municípios durante aplicação do questionário no intuito de identificar a realização, em especial dos serviços clínicos desenvolvidos por farmacêuticos.

No primeiro contato no território, o secretário municipal de saúde e/ ou o responsável pela assistência farmacêutica, apontavam para o entrevistador, os estabelecimentos de saúde que realizavam entrega e/ ou dispensação dos medicamentos para que em seguida ocorresse à aplicação do questionário para o profissional entrevistado nos estabelecimentos identificado como farmácia de edificação exclusiva ou como um dos setores do referido estabelecimento.

\section{A coleta de dados nos estabelecimentos de saúde}

O profissional de saúde responsável pelo serviço de farmácia foi identificado no estabelecimento, sendo convidado a participar da pesquisa e em seguida aplicouse o questionário complementado ao fim da entrevista pelo preenchimento da observação do entrevistador (BRASIL, 2013).

A análise dos dados para Ponto de Atenção e Ponto de Apoio

\section{Terapêutico}

Para a análise dos dados da pesquisa foi utilizado o programa estatístico IBM SPSS Statistics 20 sendo incluídos os resultados obtidos nas entrevistas realizadas no território e as respostas passaram pela análise descritiva exploratória das variáveis ou critérios envolvidos no estudo.

Foi realizado um recorte do questionário que definia as variáveis que envolviam serviços clínicos para caracterizar as ações e serviços de saúde do 
estabelecimento ou serviço "farmácia" enquanto ponto de atenção à saúde e/ ou ponto de apoio terapêutico (Quadro 1).

$\mathrm{Na}$ caracterização do Ponto de Atenção á Saúde (PAS) foi considerado quando o estabelecimento e respectivo setor ou área identificado, 'tem profissional farmacêutico (responsável técnico e/ou assistente) e realiza pelo menos um dos serviços clínicos'. Na assistência farmacêutica estes serviços de produção singular, para fins deste estudo, foram entendidos como atividades de clínica farmacêtica, que seriam categorizados como serviços técnicos assistenciais, ou seja, serviços clínicos tais como Dispensação, Orientação Terapêutica/Saúde, Seguimento Farmacoterapêutico e Conciliação de Medicamentos.

Para caracterização do Ponto de Apoio Terapêutico (PAT) foi considerado quando o profissional do estabelecimento e respectivo setor ou área identificado, referiu ofertar no mínimo um serviço ou atividade de apoio à rede regional, sendo estes relacionados à Seleção, Programação, Aquisição, Armazenagem e Distribuição de Medicamentos, a Farmacovigilância e Estudos de Utilização de Medicamentos (EUM), a Entrega de Medicamentos ao usuário, que para o estudo, corresponde ao fornecimento de medicamentos por profissional, inclusive farmacêutico, nos estabelecimentos de saúde, mediante apresentação de prescrição, seja em receituário específico ou por meio de registro em prontuário, sem que se realizem serviços clínicos farmacêuticos inerentes ao ponto de atenção.

Para a caracterização do PAT considerou-se quando o estabelecimento ofertava pelo menos um dos serviços farmacêuticos gerenciais na forma de apoio para os demais pontos de atenção da RAS.

\section{Princípios éticos da pesquisa}

Os instrumentos, dados coletados e resultados deste estudo são parte do projeto de pesquisa denominado 'A Assistência Farmacêutica nas Redes de Atenção à Saúde: Um Recorte nas Regiões do Projeto QualiSUS-Rede', aprovado pelo Comitê Nacional de Ética em Pesquisa (CONEP), processo CAAE 19554413.6.0000.0008, tendo como fonte financiadora o Ministério da Saúde, sendo, portanto, os princípios éticos assegurados. 
Quadro 1. Critérios para caraterização em Ponto de Atenção à Saúde (PAS) e/ ou Ponto de Apoio Terapêutico (PAT) dos estabelecimentos de saúde relacionados à assistência farmacêutica a partir da oferta de serviços.

Ponto de Atenção à Saúde (PAS)

(Serviços Técnicos Assistenciais de Clínica Farmacêutica)

Dispensação de Medicamentos

Orientação Terapêutica

Seguimento Farmacoterapêutico

Conciliação Terapêutica

Revisão da Farmacoterapia
Ponto de Apoio Terapêutico (PAT)

(Serviços Técnicos Gerenciais de Apoio a RAS)
Seleção de Medicamentos

Programação de Medicamentos

Aquisição de Medicamentos

Armazenagem de Medicamentos

Distribuição de Medicamentos

Farmacovigilância e Estudo de Utilização

Medicamentos (EUM)

Entrega de medicamentos

Fonte: Elaborado pelo autor com base com base na Portaria MS no 4.279 (Brasil, 2010) e Documento Técnico do Ministério da Saúde denominado "A assistência farmacêutica nas Redes de Atenção à Saúde no SUS". (Brasil, 2012).

\section{RESULTADOS}

Ao analisar as informações coletadas no CNES e aplicando os critérios de inclusão na pesquisa para caracterização do ponto de atenção à saúde (PAS), dos 156 estabelecimentos identificados com CNES, 143 estavam ativos até setembro 2013, sendo eles classificados em: posto de saúde 14, centro de saúde/unidade básica 72, unidade mista 1 , secretaria de saúde 7, centro de atenção psicossocial 6 , unidade de apoio diagnose e terapia (serviço de apoio à diagnose e terapia isolado) 11 , clinica/centro de especialidade 6 , hospital geral 5 , centro de apoio a saúde da família 2, unidade móvel terrestre 1, consultório isolado 11, unidade móvel de nível pré-hospitalar na área de urgência 4, farmácia 1, polo academia da saúde 1 , policlínica 1.

Dos estabelecimentos ativos 79 (55\%) informaram código 03 (serviço de apoio - farmácia) e em 63 (44\%), o gestor municipal ou o responsável pela AF do município, identificou que realizava a entrega e/ ou dispensação de medicamentos a usuários. Os dados coletados nestas unidades foram trabalhados buscando a caracterização de tipo de estabelecimento, serviços e informação de serviços de farmácia de acordo com informações do CNES e SIA desenhando a conformação da $5^{\mathrm{a}} \mathrm{RS}$ no tocante a AF na rede assistencial (Tabela 1 ).

Dois municípios apresentaram uso acumulativo do CNES para mais de um estabelecimento e ambos foram incluídos para aplicação do instrumento. Porém, um 
dos 65 questionários foi excluído por se tratar de estabelecimento que não atendia ao critério de inclusão (entrega e/ ou dispensação de medicamentos), totalizando 64 questionários aplicados oriundos de 63 estabelecimentos ou CNES ativos.

Tabela 1. Caracterização dos estabelecimentos de saúde da $5^{\mathrm{a}}$ RS segundo o tipo, serviços e informação de serviços de farmácia de acordo com Cadastro Nacional de Estabelecimentos de Saúde e Sistema de Informação Ambulatorial. Alagoas, Setembro 2013.

\begin{tabular}{|c|c|c|c|c|c|c|c|}
\hline Municípios & $\begin{array}{c}\text { Total } \\
\text { de } \\
\text { CNE } \\
\text { S }\end{array}$ & $\begin{array}{c}\text { No de } \\
\text { CNE } \\
\text { S } \\
\text { Ativo } \\
\text { s }\end{array}$ & $\begin{array}{l}\text { № de CNES } \\
\text { com tipo de } \\
\text { estabelecime } \\
\text { nto (cód. } 43 \text { )* }\end{array}$ & $\begin{array}{c}\text { № de CNES } \\
\text { com } \\
\text { serviços } \\
\text { especializa } \\
\text { dos (cód. } \\
125 \text { ) }\end{array}$ & $\begin{array}{c}\text { № de CNES } \\
\text { com } \\
\text { classificação } \\
\text { de serviço } \\
\text { especializado } \\
\text { (cód. } 001 \text { a } \\
007)^{\star \star}\end{array}$ & $\begin{array}{c}\text { № de } \\
\text { CNES } \\
\text { com } \\
\text { Serviço } \\
\text { de Apoio } \\
\text { (cód. 03) }\end{array}$ & $\begin{array}{c}\text { № de CNES } \\
\text { com } \\
\text { Produção de } \\
\text { Serviços de } \\
\text { Farmácia no } \\
\text { SIA-SUS }\end{array}$ \\
\hline Município 1 & 30 & 27 & 1 & 1 & 1 & 21 & 1 \\
\hline Município 2 & 20 & 18 & - & - & - & 13 & - \\
\hline Município 3 & 20 & 18 & - & - & - & 5 & - \\
\hline Município 4 & 26 & 26 & - & 1 & 1 & 2 & - \\
\hline Município 5 & 4 & 4 & - & - & - & 3 & - \\
\hline Município 6 & 40 & 36 & - & - & - & 24 & - \\
\hline Município 7 & 16 & 14 & - & - & - & 11 & - \\
\hline Total & 156 & 143 & 1 & 2 & 2 & 79 & 1 \\
\hline
\end{tabular}

Fonte: Cadastro Nacional e Estabelecimentos de Saúde (CNES), Sistema de Informações Ambulatoriais do SUS (SIA-SUS), setembro 2013.

*Tipo de Estabelecimento cód. 43 (Farmácia) - Farmácia em edificação exclusiva;

**Classificação do Serviço Especializado cód. 125 (Serviço de Farmácia): 001- Dispensação de Medicamentos do Componente Especializado da Assistência Farmacêutica; 002- Farmácia Popular; 003Farmácia com Manipulação Homeopática; 004- Dispensação de Medicamentos Estratégicos; 005Dispensação de Medicamentos Básicos; 006- Farmácia Hospitalar; 007- Farmácia Viva.

${ }^{\star \star \star}$ Códigos SIA: 03.01.01.003-0 - Consulta de Profissionais de Nível Superior na Atenção Básica (Exceto Médico), 03.01.01.004-8 - Consulta de Profissionais de Nível Superior na Atenção Especializada (Exceto Médico), ambos obtidos para a produção do código de Classificação Brasileiro de Ocupações no 223405.

Para análise dos dados das entrevistas foi necessário definir o número de estabelecimentos de saúde por município que de acordo com a classificação do CNES que atendeu aos critérios de inclusão na pesquisa. Não foram identificadas, nos sistemas de produções ambulatorial e hospitalar, informações relacionadas à produção dos serviços de farmácia na região.

Os dados obtidos a partir do CNES demonstraram que os Serviços de Apoio Farmácia (código 03) totalizaram 79 estabelecimentos de saúde, porém destes 63 atenderam os critérios de inclusão no estudo e aplicação do questionário para caracterização dos PAS e PAT, onde se entregavam e/ ou dispensavam medicamentos e apenas 2 estabelecimentos informaram serviços de farmácia com código 125.

Os resultados das entrevistas apontaram que 19\% dos estabelecimentos realizavam com alguma frequência a 'entrega de medicamento ao usuário com 
orientação pelo farmacêutico', porém na observação direta e diário de campo dos entrevistadores apenas $1 \%$ de fato realizava esse tipo de serviço com a orientação do farmacêutico. Apontaram também que $17 \%$ dos estabelecimentos realizavam seguimento farmacoterapêutico, porém nenhum dos estabelecimentos de saúde apresentou o farmacêutico como responsável por esse tipo de serviço e no tocante a conciliação de medicamentos e revisão da farmacoterapia, estas não foram citadas por nenhum dos entrevistados, não sendo atribuída a nenhum profissional, inclusive o farmacêutico.

Tabela 2. Estabelecimentos de saúde da $5^{\mathrm{a}} \mathrm{RS}$ que atenderam os critérios de inclusão no estudo para Ponto de Atenção à Saúde (PAS) e Ponto de Apoio Terapêutico (PAT) segundo tipo, serviços especializados e informação de serviços de farmácia de acordo com o CNES. Setembro. 2013.

\begin{tabular}{lcccc} 
Municípios & $\begin{array}{c}\text { Estabelecimentos } \\
\text { com Serviço de } \\
\text { Apoio (cód. 03) }\end{array}$ & $\begin{array}{c}\text { Estabelecimentos } \\
\text { que entregam e/ ou } \\
\text { dispensam } \\
\text { medicamentos }\end{array}$ & $\begin{array}{c}\text { Estabelecimentos } \\
\text { que atenderam os } \\
\text { critérios do estudo } \\
\text { para PAS }\end{array}$ & $\begin{array}{c}\text { Estabelecimentos } \\
\text { que atenderam os } \\
\text { critérios do estudo } \\
\text { para PAT }\end{array}$ \\
\hline Município 1 & 21 & 12 & 1 & 12 \\
Município 2 & 13 & 11 & - & 11 \\
Município 3 & 5 & 10 & - & 10 \\
Município 4 & 2 & 8 & 1 & 8 \\
Município 5 & 3 & 2 & - & 2 \\
Município 6 & 24 & 11 & - & 11 \\
Município 7 & 11 & 9 & - & 9 \\
Total & 79 & 63 & 2 & 63 \\
\hline
\end{tabular}

Fonte: Cadastro Nacional e Estabelecimentos de Saúde (CNES) e Sistema de Informações Ambulatoriais do SUS (SIA-SUS), Setembro de 2013.

A Tabela 3 demonstra a distribuição quantitativa dos serviços farmacêuticos clínicos por município da $5^{\mathrm{a}} \mathrm{RS}$ e quais dos serviços podem ser caracterizados, de acordo com os critérios estabelecidos no estudo, para a caracterização do Ponto de Atenção à Saúde (PAS). Dos 63 estabelecimentos de saúde visitados na pesquisa, apenas 2 atenderam pelo menos um dos critérios para caracterizar o PAS e em nenhum dos pontos 0 profissional farmacêutico realizava seguimento farmacoterapêutico.

Tabela 3. Estabelecimentos de saúde da 5a RS que atendem aos critérios de caracterização em Ponto de Atenção à Saúde (PAS), baseado nos serviços técnicos assistenciais de Clínica Farmacêutica. Alagoas, Setembro de 2013.

\begin{tabular}{|c|c|c|c|c|}
\hline Municípios & $\begin{array}{c}\text { № de } \\
\text { estabelecimentos } \\
\text { com } \\
\text { Farmacêutico } \\
\text { realizando } \\
\text { entrega do } \\
\text { medicamento }\end{array}$ & $\begin{array}{c}\text { № de } \\
\text { estabelecimentos } \\
\text { com Farmacêutico } \\
\text { realizando } \\
\text { orientação no ato da } \\
\text { entrega do } \\
\text { medicamento }\end{array}$ & $\begin{array}{c}\text { № de } \\
\text { estabelecimentos } \\
\text { com Farmacêutico } \\
\text { realizando } \\
\text { seguimento } \\
\text { farmacoterapêutico }\end{array}$ & $\begin{array}{c}\text { № de } \\
\text { estabelecimentos } \\
\text { que atenderam pelo } \\
\text { menos um dos } \\
\text { critérios para PAS }\end{array}$ \\
\hline & & & & Continua \\
\hline
\end{tabular}


Conclusão

\begin{tabular}{|c|c|c|c|c|}
\hline Municípios & $\begin{array}{c}\text { № de } \\
\text { estabelecimentos } \\
\text { com } \\
\text { Farmacêutico } \\
\text { realizando } \\
\text { entrega do } \\
\text { medicamento }\end{array}$ & $\begin{array}{c}\text { № de } \\
\text { estabelecimentos } \\
\text { com Farmacêutico } \\
\text { realizando } \\
\text { orientação no ato da } \\
\text { entrega do } \\
\text { medicamento }\end{array}$ & $\begin{array}{c}\text { № de } \\
\text { estabelecimentos } \\
\text { com Farmacêutico } \\
\text { realizando } \\
\text { seguimento } \\
\text { farmacoterapêutico }\end{array}$ & $\begin{array}{c}\text { № de } \\
\text { estabelecimentos } \\
\text { que atenderam pelo } \\
\text { menos um dos } \\
\text { critérios para PAS }\end{array}$ \\
\hline Município 1 & 2 & 2 & - & 1 \\
\hline Município 2 & - & - & - & - \\
\hline Município 3 & 3 & 5 & - & - \\
\hline Município 4 & 3 & 3 & - & 1 \\
\hline Município 5 & 1 & 1 & - & - \\
\hline Município 6 & 3 & 3 & - & - \\
\hline Município 7 & - & - & - & - \\
\hline Total & 11 & 14 & - & 2 \\
\hline
\end{tabular}

Fonte: Ministério da Saúde. Secretaria de Ciência Tecnologia e Insumos Estratégicos. Departamento de Assistência Farmacêutica e Insumos Estratégicos. Recorte de resultados do piloto da pesquisa $A$ Assistência Farmacêutica nas RAS: um recorte nas regiões do projeto QualiSUS-Rede. 2013.

\section{DISCUSSÃO}

Os resultados demonstraram que a proposta de caracterização e a avaliação dos estabelecimentos de saúde da assistência farmacêutica utilizado no estudo contribuem para a estruturação da rede de atenção à saúde, identificando pontos relevantes para a gestão, especialmente quando observado o aspecto assistencial que os serviços farmacêuticos, principalmente o clínico, podem desempenhar para qualificar a gestão do cuidado, desde que se destine a atender as necessidades da população de acordo com o perfil epidemiológico do território.

$\mathrm{Na}$ perspectiva de atender o preconizado no planejamento em saúde para o SUS a partir das diretrizes para as Redes de Atenção à Saúde e sob o olhar das orientações da OMS para as chamadas Redes Integradas de Serviços de Saúde (RISS), o estudo realizou um exercício em especial que atentasse para o seu caráter ascendente, integrado e regionalizado, no intuito de se ampliar as possibilidades de adequação das regiões de saúde as necessidades de saúde da população.

Em 2011, uma pesquisa de satisfação dos usuários do SUS realizada pela ouvidoria do MS, com o objetivo de avaliar o grau de satisfação dos usuários do Sistema Único de Saúde quanto aos aspectos de acesso e qualidade percebida na atenção básica e urgência/emergência, por meio inquérito amostral, apontou como o primeiro atendimento mais procurado no SUS a consulta médica com $78,66 \%$ e em segundo medicamentos com $52,74 \%$, seguido de exames de laboratório ou imagem com $49,17 \%$ e $14,57 \%$ buscaram serviços de saúde para atendimento odontológico. 
Na visão de Pinheiro (2010) e reforçado recentemente pela OPAS (2013b), a prestação dos serviços farmacêuticos pode ser considerada como um processo chave, pois relaciona-se com a prestação direta do serviço ao público final e por isso contribui com a obtenção de resultados em saúde.

No Brasil, ainda que a prática clínica farmacêutica seja incipiente e insuficiente para atender às demandas dos usuários, as mudanças ocorridas nas últimas décadas não podem ser subestimadas. A frequência da provisão de serviços cognitivos em farmácias comunitárias e a formação de farmacêuticos mais voltados à clínica também têm aumentado (DE CASTRO, 2007)

Ao analisar a caracterização dos serviços clínicos e de apoio a rede assistencial na $5^{\mathrm{a}} \mathrm{RS}$, se observa a forte prevalência das atividades logísticas para a garantia da disponibilidade dos medicamentos ou insumos, retratados em especial pelo papel do farmacêutico enquanto agente do cuidado, que se mostra afastado, por estas demandas ou muitas vezes busca se afastar conscientemente da assistência direta ao usuário, deixando em especial essa atribuição clínica para outros profissionais.

Apesar de $17 \%$ dos entrevistados apontarem que existiam profissionais realizando serviços de seguimento farmacoterapêutico nos estabelecimentos, nenhum dos profissionais citados era o farmacêutico, reforçado pela ausência de registro físico ou eletrônico do acompanhamento terapêutico do usuário, de acordo com verificação dos entrevistadores. Esse resultado, assim como para a conciliação de medicamentos e revisão da farmacoterapia, demonstra o desconhecimento por parte deste profissional e da equipe multiprofissional dos serviços clínicos que o farmacêutico deve desenvolver no território.

Fato semelhante foi verificado na entrega de medicamento com orientação pelo farmacêutico, onde foi evidenciado que apenas 2 estabelecimentos de saúde com serviço de farmácia realizava essa atividade clínica junto aos usuários, no entanto, de acordo com o CNES a região possuía, para o período da pesquisa, 11 farmacêuticos cadastrados no sistema, com vínculo e carga horária destinada a desenvolvimento de suas funções técnico gerenciais e assistenciais. Neste caso, cabe destacar que a utilização de termos como entrega e dispensação de medicamentos pode ser facilmente confundida pelos entrevistados, uma vez que, ainda é comum o uso do termo dispensação por outros profissionais não farmacêuticos como demonstrado nos referenciais teóricos deste estudo. 
Os resultados do laboratório de inovação na atenção às condições crônicas na atenção primária, conduzido pela OPAS (2013a) no município de Curitiba, identificou que na atenção a hipertensão e Diabete Mellitus fazem parte da rotina das UBS, além das consultas e atendimentos individuais com a equipe da APS, o desenvolvimento de ações e atendimentos em grupo. Conhecidas comumente como "dia do programa de hipertensão e diabete", essas ações variam de uma UBS para outra. Na maioria delas, enfermeiros e auxiliares de enfermagem fazem anamnese rápida, aferição de indicadores como pressão arterial e peso corporal, solicitação de exames preconizados nas diretrizes clínicas, 'dispensação' de medicamentos prescritos e orientações gerais de saúde.

Essa descrição anterior de dispensação realizada por outros profissionais não farmacêuticos é muito comum no dia a dia das unidades de saúde, onde frequentemente esses profissionais utilizam equivocadamente no ato que se caracteriza pela 'entrega do medicamento' ao usuário, o termo 'dispensação', que na verdade é o ato exclusivo do farmacêutico regulamentado pelo seu conselho de classe, porém a possibilidade de distinção dos serviços farmacêuticos exclusivos ou não, ainda não está definida nos sistemas de informação do país.

O momento da dispensação é muitas vezes o único contato que o usuário tem com o farmacêutico e também o último com algum profissional de saúde antes de iniciar o tratamento da sua doença ou enfermidade (BRASIL, 2009).

A ausência de dados, atualizados e confiáveis, nos sistemas de informações, dificulta o planejamento e a definição das ações e serviços de saúde que comporiam a Relação Nacional de Ações e Serviços de Saúde (RENASES) para a assistência farmacêutica enquanto oferta dos estabelecimentos de saúde no SUS e não apenas na região e consequentemente dificultaria a qualificação para a organização e governança da RAS.

O CNES é base para operacionalizar os Sistemas de Informações em Saúde, imprescindíveis para um gerenciamento eficaz e eficiente propiciam ao gestor o conhecimento da realidade da rede assistencial existente e suas potencialidades, auxiliando no planejamento em saúde, em todos os níveis de governo, além de possibilitar maior controle social pela população (BRASIL, 2006). Logo, é fundamental sua atualização uma vez que ele permite, a partir da caracterização do serviço, que se informe, quantos e quais foram realizados pelo profissional e por estabelecimento, frente à necessidade da população da região. 
$\mathrm{Na}$ descrição dos serviços farmacêuticos do Quadro 1, propõe-se uma composição mínima de ofertas assistenciais e gerenciais que são necessárias para se caracterizar os serviços farmacêuticos dentro desta rede regional, entendendo sua complexidade e sua permanente mudança de conformação frente às dificuldades inerentes a gestão pública no país, vislumbrando a composição do Mapa da Saúde com maior fidedignidade para se identificar de fato as ações e serviços de saúde para a construção da RENASES, bem como da Programação Geral das Ações e Serviços de Saúde (PGASS).

É sob a perspectiva da organização em rede que Silva, et al. (2013), descreve as RAS no SUS, como uma malha que interconecta e integra os estabelecimentos e serviços de saúde de determinado território, organizando-os sistematicamente para os diferentes níveis e densidades tecnológicas de atenção estejam articulados e adequados para o atendimento integral ao usuário e para a promoção da saúde. Neste contexto um dos componentes indispensáveis é a assistência farmacêutica e esta devendo se articular com outros dentro do modelo de atenção que supere a atenção as condições agudas e se volte ao enfrentamento das condições ou doenças crônicas, por meio de linhas de cuidado, abrangendo aí a prevenção à cura e reabilitação do usuário.

A partir da caracterização dos serviços farmacêuticos em ponto de atenção à saúde e/ ou ponto de apoio terapêutico inicia-se a construção e conformação de uma carteira de serviços, que passa a compor a RENASES específica para o Sistema de Assistência Farmacêutica no SUS e consequentemente a PGASS, sendo esta única para a região. Esses serviços devem ser inseridos no CNES e ofertados de acordo com a necessidade da região de saúde, para em seguida serem informados, enquanto produção dos profissionais, nos sistemas ambulatoriais e hospitalares do país.

A ausência ou subutilização de dados a partir de sistemas de informação nacionais, a exemplo do CNES e SIA, de acordo com os resultados do estudo, dificulta a caracterização da farmácia em um estabelecimento de saúde com edificação exclusiva ou enquanto parte ou setor integrante de outro estabelecimento. Percebe-se, portanto, que os dados obtidos a partir destes sistemas de informação dificultam a identificação das atividades que vão para além do processo logístico da assistência farmacêutica, diferente de outros países, que inseriram nos sistemas de 
saúde os serviços como parte da oferta baseada nas necessidades epidemiológicas de seus territórios e que se ampliam quando o objetivo é o cuidado ao usuário.

Lopez-Valcárcel (2006), descreve o sistema de saúde espanhol como um exemplo dessa oferta, uma vez que se utiliza da definição dos serviços de saúde a partir de um perfil demográfico que justifique o tipo e as responsabilidades na sua organização, onde as chamadas comunidades autônomas apontam, com base em alguns parâmetros definidos pelo Ministério da Saúde da Espanha, onde se alocariam os serviços de acordo com a demanda e à medida que essa população adscrita aumenta, paralelamente, a carteira de serviços prestados na rede de saúde passa a agregar serviços especializados.

As necessidades da população vão além da questão do acesso e da qualidade dos produtos farmacêuticos, requerendo ações articuladas ao processo de atenção à saúde que possam garantir a continuidade do cuidado, bem como a prevenção e resolução de problemas ligados à farmacoterapia. Uma nova Assistência Farmacêutica integrada de forma singular ao processo de cuidado em saúde se faz necessária, a fim de dar resposta à nova situação farmacoepidemiológica que ora se apresenta. A população deve ser assistida por ações de complexidade compatível com sua estratificação de risco, tanto no que diz respeito ao processo saúde-doença, como com relação ao risco de morbimortalidade relacionada aos medicamentos (CORRER, 2011).

$\mathrm{Na}$ visão de Hartz e Contandriopoulos (2004), sobre a natureza do objeto "rede", uma dupla leitura torna-se indispensável: como estrutura organizacional, voltada para a produção de serviços, e como uma dinâmica de atores em permanente renegociação de seus papéis, favorecendo novas soluções para velhos problemas num contexto de mudanças e compromissos mútuos.

No Brasil, o que se propôs com certa similaridade a carteira de serviços de saúde espanhola foi a Relação Nacional de Ações e Serviços de Saúde (RENASES) que se encontra em construção pelos entes federados, porém em especial no tocante a assistência farmacêutica, para que tenhamos como organizá-la de forma transversal e integrada minimamente as ações e serviços preconizados pelo Decreto 7.508/2011, como atenção primária/ básica, urgência e emergência, atenção psicossocial, atenção ambulatorial especializada e hospitalar, bem como vigilância em saúde passa pela definição de quais serviços serão ofertados nos diferentes níveis de complexidade do SUS (BRASIL, 2011). 
Na perspectiva de atender o preconizado no planejamento em saúde para 0 SUS a partir das diretrizes para as Redes de Atenção à Saúde e sob o olhar das orientações da OMS para as chamadas Redes Integradas de Serviços de Saúde (RISS), o estudo realizou um exercício em especial que atentasse para o seu caráter ascendente, integrado e regionalizado, no intuito de se ampliar as possibilidades de adequação das regiões de saúde as necessidades de saúde da população.

Os princípios e as diretrizes do SUS não poderão ser concretizados, na prática dos serviços, sem a compreensão da necessidade da efetivação da Assistência Farmacêutica como uma política pública de saúde. Para isso, a sua estruturação torna-se um grande desafio para os gestores e profissionais de saúde, com destaque para o campo farmacêutico. Mesmo considerando a complexidade do processo de Assistência Farmacêutica, que envolve a articulação e sincronismo entre os serviços e a ação cooperativa dos profissionais de saúde, observam-se desde 2003 avanços na organização dessa política e no seu financiamento (BRASIL, 2012).

Desta forma, ao propor a caracterização mínima do Ponto de Atenção à Saúde e do Ponto de Apoio Terapêutico na perspectiva da Assistência Farmacêutica, podendo ou não um mesmo estabelecimento atender simultaneamente as duas propostas para caracterização de serviços farmacêuticos, observando neste caso os apontamentos de Silva, et al. (2013), se exercitou frente aos conceitos e diretrizes apontados nas RAS, em especial para o chamado planejamento ascendente, uma estrutura mínima de serviços para se compor o mapa da saúde onde a assistência farmacêutica, de acordo com a proposta do estudo, se caracterizaria no território desde uma unidade básica de saúde até a mais alta complexidade de ações e serviços de saúde.

O exercício de caracterização dos pontos apresentados neste estudo se configura como um instrumento fundamental na fase de elaboração do Mapa da Saúde e de sua permanente atualização, determinando inclusive geograficamente a distribuição de recursos humanos e de ações e serviços ofertados pelo SUS na região de saúde, inclusive pela iniciativa privada, para que sejam contempladas e adequadas a partir da RENASES e programados na PGASS, para em um passo seguinte os entes contratualizem por meio do Contrato Organizativo de Ação Pública da Saúde (COAP). 
Neste sentido, a Assistência Farmacêutica que para Mendes (2012), é um dos Sistemas de Apoio dentro da estrutura operacional das Redes de Atenção à Saúde e que segundo Lavras (2010), estaria atribuído ao ponto de apoio diagnóstico e terapêutico, no tocante ao serviço de dispensação de medicamento, de acordo com os dados do estudo, não poderia se limitar unicamente a apoio aos pontos de atenção da rede, mas sim, como descreve o próprio Ministério da Saúde (2012), ou seja, os estabelecimentos de saúde envolvidos com entrega e/ ou dispensação de medicamentos, a partir de seus serviços ofertados, hora se conformariam em ponto de apoio terapêutico, hora em ponto de atenção à saúde, ou mesmo de forma simultânea em ambos, porém este último atrelado a caraterização e a oferta de serviços clínicos aos usuários.

Portanto, a farmácia neste contexto poderia se conformar em um ponto de apoio terapêutico, fortalecendo a proposta de sistema de apoio da RAS, voltado aos pontos de atenção e também poderia se conformar, de forma isolada ou simultaneamente em ponto de atenção à saúde, no momento que o profissional farmacêutico atendesse a necessidade de serviços clínicos para o território, o que foi identificado na pesquisa em apenas $1 \%$ dos estabelecimentos da $5^{\mathrm{a}} \mathrm{RS}$.

\section{Limitações do estudo}

A ausência de pergunta que identificasse a conciliação de medicamentos e revisão da farmacoterapia enquanto registro dos serviços clínicos para o estabelecimento de saúde pode ser limitadora, porém mesmo tendo a opção de campo aberto para resposta, este tipo de serviço não foi citado nas entrevistas. A pouca referência na literatura sobre a organização da assistência farmacêutica no contexto da rede integrada de serviços de saúde, em especial na América Latina, limitou a comparação no tocante aos aspectos regionais que poderiam ser identificados no estudo. As farmácias comerciais da iniciativa privada, inclusive as participantes do Programa Farmácia Popular do Brasil na modalidade 'Aqui tem Farmácia Popular', por não possuírem CNES, limitam um dos aspectos relacionados ao mapa da saúde no tocante à estrutura operacional da RAS para o território, mesmo que elas não realizassem prestação de serviços diretamente ao SUS.

\section{REFERÊNCIAS}


ARAÚJO, A.L.A.; Pereira, L. R. L.; UETA, J.M. FREITAS, O.; Perfil da assistência farmacêutica na Atenção Primária em Saúde do SUS. Ciência \& Saúde Coletiva, 13(Sup): 611-617, 2008.

BRASIL. Ministério da Saúde. Departamento de Informática do SUS - DATASUS. Cadastro Nacional de Estabelecimentos de Saúde - CNES. Disponível em: http://www.cnes.datasus.gov.br/. Acesso em: 01 de outubro $2013 b$.

BRASIL. Ministério da Saúde. Portaria n 4279 de 30 de Dezembro de 2010, Aprova as Diretrizes para a Organização da Rede de Atenção à Saúde do SUS, e dá outras providências, Diário Oficial da República Federativa do Brasil, Brasília, DF, 30 de dezembro de 2010.

BRASIL. Ministério da Saúde. Secretaria de Ciência, Tecnologia e Insumos Estratégicos. Departamento de Assistência Farmacêutica e Insumos Estratégicos. Planejar é preciso: uma proposta de método para aplicação à assistência farmacêutica / Ministério da Saúde, Secretaria de Ciência, Tecnologia e Insumos Estratégicos, Departamento de Assistência Farmacêutica e Insumos Estratégicos. Brasília: Editora do Ministério da Saúde, 2006. 74 p.

BRASIL. Ministério da Saúde. Secretaria de Ciência, Tecnologia e Insumos Estratégicos. Departamento de Assistência Farmacêutica e Insumos Estratégicos. Diretrizes para estruturação de farmácias no âmbito do Sistema Único de Saúde / Ministério da Saúde, Secretaria de Ciência, Tecnologia e Insumos Estratégicos, Departamento de Assistência Farmacêutica e Insumos Estratégicos. Brasília: Ministério da Saúde, 2009. 44 p.

BRASIL. Ministério da Saúde. Secretaria de Gestão Estratégica e Participativa Ouvidoria do SUS. Relatório da Pesquisa de Satisfação dos Usuários do SUS quanto aos aspectos de acesso e qualidade percebida na atenção à saúde, mediante inquérito amostral. Ouvidoria Geral do SUS Coordenação Geral de Pesquisa e Processamento de Demandas Núcleo de Pesquisa e Relatórios, 2011. p.7.

BRASIL. Presidência da República. Decreto 7.508 de 28 de junho de 2011. Regulamenta a Lei no 8.080, de 19 de setembro de 1990, para dispor sobre a 
organização do Sistema Único de Saúde - SUS, o planejamento da saúde, a assistência à saúde e a articulação interfederativa, e dá outras providências. Diário Oficial da República Federativa do Brasil, Brasília, DF, 29 de junho de 2011. Disponível em http://www.brasilsus.com.br/legislacoes/gm/108599-7508.html. Acesso em: julho de 2013.

CORRER, C.J.; OTUKI, M.F.; SOLER, O.; Assistência farmacêutica integrada ao processo de cuidado em saúde: gestão clínica do medicamento. Rev Pan-Amaz Saude $2011 ; 2(3): 41-49$

DE CASTRO M.S.; CORRER C.J.; Pharmaceutical care in community pharmacies: practice and research in Brazil. Ann Pharmacother 2007; 41:148693.

HARTZ Z.M.; CONTANDRIOPOULOS A.P.; Integralidade da atenção e integração de serviços de saúde: desafios para avaliar a implantação de um "sistema sem muros."Cad Saude Publica [Internet]. 2004/12/21 ed. 2004;20 (Suppl 2):S331-6. Available from: http://www.ncbi.nlm.nih.gov/entrez/query.fcgi?cmd=Retrieve\&db=PubMed\&dopt=Cita tion\&list_uids $=15608945$

LAVRAS, C.C.C. Descentralização, regionalização e estruturação de redes regionais de atenção à saúde no SUS. In: IBANES, N; ELIAS, P. E. M.; SEIXAS, P. H. D’ANGELO. Política e Gestão Pública em Saúde. São Paulo: Hucitec Editora: Cealag, 2011.

LOPEZ-VALCÁRCEL, Beatriz Goncálvez. "Políticas contractuales em atencion especializada". In: José R. Repullo e Antonio Iñesta (orgs.) Sistemas y servicios sanitários. Madri. Diz de Santos, 2006.

MENDES, E.V. O cuidado das condições crônicas na atenção primária à saúde: o imperativo da consolidação da estratégia da saúde da família [Internet]. Brasília: Organização Pan-Americana da Saúde; 2012. Available from: http://apsredes.org/site2012/wpcontent/uploads/downloads/2012/04/RedesdeAtencao condicoescronicas.pdf. 
OPAS. Brasil, Conselho Nacional de Secretários de Saúde. A implantação do modelo de atenção às condições crônicas em Curitiba: resultados do laboratório de inovação sobre atenção às condições crônicas na atenção primária em saúde. Brasília, DF: OPAS, p.185, 2013a.

ORGANIZACIÓN PANAMERICANA DE LA SALUD. "Redes Integradas de Servicios de Salud: Conceptos, Opciones de Política y Hoja de Ruta para su Implementación en las Américas” Washington, D.C.: OPS, (C 2010.

ORGANIZACIÓN PANAMERICANA DE LA SALUD. Servicios farmacéuticos basados en la atención primaria de salud. Documento de posición de la OPS/OMS. Washington, DC : OPS, 2013b.

PINHEIRO, M.R.; Serviços Farmacêuticos na Atenção Primária à Saúde. Revista Tempus Actas Saúde Coletiva. Universidade de Brasília. Vol. 4 . n. 3, 2010. p.15-22.

PUIG, P. L.; CARBONELL, L. A.; DÍAZ, I. E. F.; ALBAJÉS, C. R.; PÉREZ, A. M. S.; BARRERA, O. S.; Nivel de integración del Sistema Nacional de Salud Cubano. Revista Cubana de Medicina General Integral. vol. 27 no.4 Ciudad de La Habana oct.-dic. 2011.

SILVA, S. F.; CARVALHO, G.C.M.; MIRANDA, H.M.J.; MEDEIROS, J.; SANTOS, L.; ANDRADE, L.O.M.; JUNIOR, N.B.; Redes de atenção à saúde: desafios da regionalização no SUS/ organizador: Silvio Fernandes da Silva; Campinas, SP: Saberes Editora, 2013. 249 p.

TAVARES, N.U.L.; BERTOLDI, A. D, THUMÉ, E.; FACCHINI, L. A.; DE FRANÇA, G. V. A.; MENGUE, S. S.; Adesão ao tratamento medicamentoso em idosos. Rev Saúde Pública 2013;47(6):1092-101. 


\section{CONSIDERAÇÕES FINAIS}

Os achados demonstraram que a caracterização proposta neste estudo pode ser aplicada para a assistência farmacêutica enquanto instrumento auxiliar em uma das etapas que envolve o processo de planejamento no SUS, sendo inclusive reproduzida em diferentes realidades regionais, apontando a necessidade de melhorias nos sistemas de informação e na qualificação da gestão do cuidado, especialmente quando observadas as diretrizes para estruturação das redes de atenção e a organização da oferta de serviços regionais, a partir do diagnóstico dos estabelecimento de saúde.

Ficou evidente ainda, a necessidade de fontes de dados oficiais confiáveis, porém o que se evidenciou para a região do estudo, foi à fragilidade das informações dos sistemas CNES e SIA para subsidiar as decisões de organização da assistência farmacêutica na rede regional de atenção à saúde.

Essas constatações apontam para um desconhecimento técnico pelos profissionais da assistência farmacêutica e da área de planejamento na maioria dos municípios da região, quanto às plataformas disponibilizadas no SUS para cadastro e produção de serviços, bem como a subutilização das mesmas, deixando, portanto, de utilizá-los como fonte de informação para o planejamento na gestão, prejudicando o processo de tomada de decisão pelos gestores.

A ausência de registros eletrônicos em saúde e sistemas integrados dificultam ainda mais a gestão regional e sua governança, ficando evidente a necessidade de melhorar as descrições ou definições das ações e serviços de saúde, neste caso para a assistência farmacêutica, bem como a atualização permanente destas bases de dados.

Outro aspecto apontado no estudo e que envolve os sistemas de informações, é a ausência de instrumentos ou ferramentas complementares a estas bases que validem esta caracterização proposta no estudo, de forma ágil e periódica, com regras claras de utilização e responsabilização pelas informações referidas no sistema.

Os serviços farmacêuticos que compuseram a caracterização da região e de seus estabelecimentos no estudo demonstram a quase ausência de serviços clínicos 
desenvolvidos pelos farmacêuticos na região e o seu afastamento da gestão do cuidado no território.

Logo, a programação de ações e serviços na região deveria ser pensada e oferta, em especial para os serviços clínicos, a partir das necessidades da população adscrita do território, com base nos dados e perfis epidemiológicos e nosológicos e observando a capacidade instalada de estabelecimentos como as farmácias.

O desenvolvimento do planejamento deve, portanto, ser articulado, hora com o papel de atenção à saúde do usuário, integrada com as atividades multiprofissionais, hora desenhada no seu contexto de apoio a rede assistencial, ou seja, que envolvem as atividades logísticas ou de abastecimento, bem como as de farmacoepidemiologia como farmacovigilância e estudos sobre utilização de medicamentos priorizando neste caso o apoio aos pontos de atenção à saúde com as informações produzidas a partir destes serviços.

Esta prática pode e deve ser amadurecida enquanto estratégia de fortalecimento de políticas públicas, neste caso especial voltado a Política Nacional de Assistência Farmacêutica no SUS, para que de fato se planeje apontando as necessidades de ações e serviços de saúde, bem como de investimentos não apenas nas estruturas físicas dos estabelecimentos, mas na qualificação profissional voltada as práticas clínicas e ao cuidado, sem deixar de lado a garantia do acesso ao medicamento e dos fundamentos das RAS que observam a economia de escala, qualidade, suficiência, acesso e disponibilidade de recursos. 


\section{REFERÊNCIAS}

ARAÚJO, A.L.A.; Pereira, L. R. L.; UETA, J.M. FREITAS, O.; Perfil da assistência farmacêutica na Atenção Primária em Saúde do SUS. Ciência \& Saúde Coletiva, 13(Sup):611-617, 2008.

BRASIL. Ministério da Saúde. Departamento de Informática do SUS - DATASUS. Cadastro Nacional de Estabelecimentos de Saúde - CNES. Disponível em: http://www.cnes.datasus.gov.br/.Acesso em: 01 de outubro 2013b.

. Ministério da Saúde. Departamento de Informática do SUS - DATASUS.

Sistema de Informações Ambulatoriais (SIA) do Sistema Único de Saúde. Disponível em: http://www.sia.datasus.gov.br/. Acesso em: 01 de outubro 2013b.

. Ministério da Saúde. Portaria o 4279 de 30 de Dezembro de 2010, Aprova as Diretrizes para a Organização da Rede de Atenção à Saúde do SUS, e dá outras providências, Diário Oficial da República Federativa do Brasil, Brasília, DF, 30 de dezembro de 2010.

Ministério da Saúde. Secretaria de Ciência, Tecnologia e Insumos Estratégicos. Departamento de Assistência Farmacêutica e Insumos Estratégicos. Planejar é preciso: uma proposta de método para aplicação à assistência farmacêutica / Ministério da Saúde, Secretaria de Ciência, Tecnologia e Insumos Estratégicos, Departamento de Assistência Farmacêutica e Insumos Estratégicos. Brasília: Editora do Ministério da Saúde, 2006. 74 p.

- Ministério da Saúde. Secretaria de Ciência, Tecnologia e Insumos Estratégicos. Departamento de Assistência Farmacêutica e Insumos Estratégicos. Diretrizes para estruturação de farmácias no âmbito do Sistema Único de Saúde / Ministério da Saúde, Secretaria de Ciência, Tecnologia e Insumos Estratégicos, Departamento de Assistência Farmacêutica e Insumos Estratégicos. Brasília: Ministério da Saúde, 2009. 44 p.

Ministério da Saúde. Secretaria de Gestão Estratégica e Participativa Ouvidoria do SUS. Relatório da Pesquisa de Satisfação dos Usuários do SUS quanto aos aspectos de acesso e qualidade percebida na atenção à saúde, 
mediante inquérito amostral. Ouvidoria Geral do SUS Coordenação Geral de Pesquisa e Processamento de Demandas Núcleo de Pesquisa e Relatórios, 2011. p.7.

Presidência da República. Decreto 7.508 de 28 de junho de 2011. Regulamenta a Lei o 8.080, de 19 de setembro de 1990, para dispor sobre a organização do Sistema Único de Saúde - SUS, o planejamento da saúde, a assistência à saúde e a articulação interfederativa, e dá outras providências. Diário Oficial da República Federativa do Brasil, Brasília, DF, 29 de junho de 2011. Disponível em http://www.brasilsus.com.br/legislacoes/gm/108599-7508.html. Acesso em: julho de 2013.

CECÍLIO, L.C.O., MERHY, E.E. A Integralidade do Cuidado como Eixo da Gestão Hospitalar. Campinas-SP, março de 2003, p.

CORRER, C.J.; OTUKI, M.F.; SOLER, O.; Assistência farmacêutica integrada ao processo de cuidado em saúde: gestão clínica do medicamento. Rev Pan-Amaz Saude $2011 ; 2(3): 41-49$

COSTA, K.S. \& NASCIMENTO JR, J.M. HÓRUS: Inovação tecnológica na Assistência Farmacêutica no Sistema Único de Saúde. Revista de Saúde Pública. Dez 2012. Vol.46, suppl.1, p.91-99.

DE CASTRO, M.S.; CORRER, C.J.; Pharmaceutical care in community pharmacies: practice and research in Brazil. Ann Pharmacother 2007; 41:148693.

HARTZ Z.M.; CONTANDRIOPOULOS A.P.; Integralidade da atenção e integração de serviços de saúde: desafios para avaliar a implantação de um "sistema sem muros."Cad Saude Publica [Internet]. 2004/12/21 ed. 2004;20(Suppl 2):S331-6. Available from: http://www.ncbi.nlm.nih.gov/entrez/query.fcgi?cmd=Retrieve\&db=PubMed\&dopt=Cita tion\&list_uids $=15608945$

KUSCHNIR, R.; CHORNY, A.H. Redes de atenção à saúde: contextualizando o debate. Ciênc. saúde coletiva [online]. 2010, vol.15, n.5, pp. 2307-2316. ISSN 14138123. 
LAVRAS, C.C.C. Descentralização, regionalização e estruturação de redes regionais de atenção à saúde no SUS. In: IBANES, N; ELIAS, P. E. M.; SEIXAS, P. H. D’ANGELO. Política e Gestão Pública em Saúde. São Paulo: Hucitec Editora: Cealag, 2011.

LIMA, C.R.A, SCHRAMM, J.M.A., COELI. C.M.; SILVA, M.E.M. Revisão das dimensões de qualidade dos dados e métodos aplicados na avaliação dos sistemas de informação em saúde. Cad Saude Publica. 2009;25(10):2095-109.

LOPEZ-VALCÁRCEL, Beatriz Goncálvez. "Políticas contractuales em atencion especializada". In: José R. Repullo e Antonio Iñesta (orgs.) Sistemas y servicios sanitários. Madri. Diz de Santos, 2006.

MENDES, E. V. As redes de atenção à saúde. / Eugênio Vilaça Mendes. Brasília: Organização Pan-Americana da Saúde, 2011. 549 p.: il.

MENDES, E.V. $O$ cuidado das condições crônicas na atenção primária à saúde: - imperativo da consolidação da estratégia da saúde da família [Internet]. Brasília: Organização Pan-Americana da Saúde; 2012. Available from: http://apsredes.org/site2012/wp-

content/uploads/downloads/2012/04/RedesdeAtencao condicoescronicas.pdf.

OPAS. Brasil, Conselho Nacional de Secretários de Saúde. A implantação do modelo de atenção às condições crônicas em Curitiba: resultados do laboratório de inovação sobre atenção às condições crônicas na atenção primária em saúde. Brasília, DF: OPAS, p.185, 2013a.

ORGANIZACIÓN PANAMERICANA DE LA SALUD. "Redes Integradas de Servicios de Salud: Conceptos, Opciones de Política y Hoja de Ruta para su Implementación en las Américas" Washington, D.C.: OPS, (C 2010.

ORGANIZACIÓN PANAMERICANA DE LA SALUD. Servicios farmacéuticos basados en la atención primaria de salud. Documento de posición de la OPS/OMS. Washington, DC : OPS, 2013b.

PINHEIRO, M.R.; Serviços Farmacêuticos na Atenção Primária à Saúde. Revista Tempus Actas Saúde Coletiva. Universidade de Brasília. Vol. 4 . n. 3, 2010. p.15-22. 
PUIG, P. L.; CARBONELL, L. A.; DÍAZ, I. E. F.; ALBAJÉS, C. R.; PÉREZ, A. M. S.; BARRERA, O. S.; Nivel de integración del Sistema Nacional de Salud Cubano. Revista Cubana de Medicina General Integral. vol.27 no.4 Ciudad de La Habana oct.-dic. 2011.

SILVA, S. F.; CARVALHO, G.C.M.; MIRANDA, H.M.J.; MEDEIROS, J.; SANTOS, L.; ANDRADE, L.O.M.; JUNIOR, N.B.; Redes de atenção à saúde: desafios da regionalização no SUS/ organizador: Silvio Fernandes da Silva; Campinas, SP: Saberes Editora, 2013. 249 p.

TANAKA, O.Y; TAMAKI, E.M. O papel da avaliação para a tomada de decisão na gestão de serviços de saúde. Ciência \& Saúde Coletiva, 17(4):821-828, 2012.

TAVARES, N.U.L.; BERTOLDI, A. D, THUMÉ, E.; FACCHINI, L. A.; DE FRANÇA, G. V. A.; MENGUE, S. S.; Adesão ao tratamento medicamentoso em idosos. Rev Saúde Pública 2013;47(6):1092-101.

VIEIRA, F.S.; Possibilidades de contribuição do farmacêutico para a promoção da saúde Ciência \& Saúde Coletiva, Temas Livres Free Themes, 12(1):213-220, 2007. 


\section{ANEXOS \\ ANEXO A - APROVAÇÃO NO COMITÊ DE ÉTICA}

\section{COMISSÃO NACIONAL DE ÉTICA EM PESQUISA}

Plataforma

\section{PARECER CONSUBSTANCIADO DA CONEP}

\section{DADOS DO PROJETO DE PESQUISA}

Título da Pesquisa: A ASSISTÊNCIA FARMACÊUTICA NAS REDES DE ATENÇĂO À SAÚDE: UM RECORTE NAS REGIÖES DO PROJETO QUALISUS-REDE

Pesquisador: KAREN SARMENTO COSTA

Área Temática:

Versäo: 3

CAAE: 19554413.6 .0000 .0008

Instituiçäo Proponente: Secretaria de Ciência e Tecnologia e Insumos Estratégicos

Patrocinador Principal: Ministério da Saúde

The Worl Bank

\section{DADOS DO PARECER}

Número do Parecer: 399.423

Data da Relatoria: 18/09/2013

Situaçăo do Parecer:

Aprovado

Consideraçōes Finais a critério da CONEP:

Diante do exposto, a Comissão Nacional de Ética em Pesquisa - CONEP, de acordo com as atribuiçőes definidas na Resolução CNS 466/2012, manifesta-se pela aprovação do projeto de pesquisa proposto.

Situaçăo: Protocolo aprovado.

Endereço: SEPN 510 NORTE, BLOCO A $1^{\circ}$ SUBSOLO, Edificio EX-INAN - Unidade II - Ministério da Saúde

Bairro: Asa Norte CEP: $70.750-521$

UF: DF

Municipio: BRASILIA

Telefone: (61)3315-5878

E-mail: conep@saude.gov.br 


\title{
ANEXO B - QUESTIONÁRIO DE RESPONSÁVEL PELO PONTO DE ATENÇÃO E/ OU PONTO DE APOIO
}

\author{
QUESTIONÁRIO DO PROJETO DE INTERVENÇÃO DA ASSISTÊNCIA FARMACÊUTICA
}

\begin{tabular}{|c|c|}
\hline \multicolumn{2}{|c|}{ DADOS DE IDENTIFICAÇÃO DA UNIDADE VISITADA (Ponto de Atenção e Apoio Terapêutico) } \\
\hline NOME DO ESTABELECIMENTO & \\
\hline ENDEREÇO & \\
\hline $\begin{array}{l}\text { RESPONSÁVEL PELA } \\
\text { INFORMAÇÃO-CARGO E } \\
\text { FUNÇÃO }\end{array}$ & \\
\hline HORÁRIO DE FUNCIONAMENTO & \\
\hline $\begin{array}{l}\text { POSSUI RESPONSÁVEL } \\
\text { TÉCNICO PELA FARMÁCIA DA } \\
\text { UNIDADE? } \\
\begin{array}{ll}\quad \text { ) Sim } & (\quad) N a ̃ o\end{array}\end{array}$ & 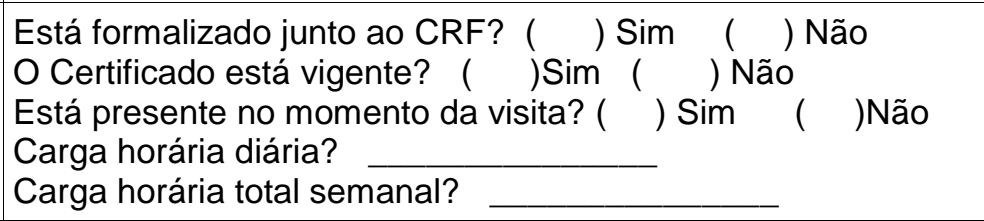 \\
\hline $\begin{array}{l}\text { POSSUI FARMACÊUTICO } \\
\text { ASSISTENTE? } \\
\begin{array}{l}\text { ( ) Sim } \quad(\quad \text { Não } \\
\text { Quantos: }\end{array}\end{array}$ & 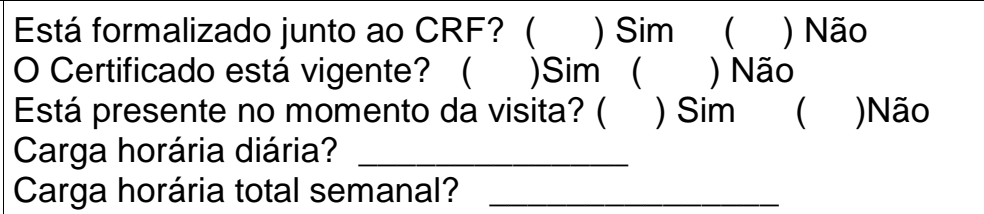 \\
\hline $\begin{array}{l}\text { № DE PROFISSIONAIS POR } \\
\text { CATEGORIA QUE ATUAM NO } \\
\text { SERVIÇO FARMACÊUTICO }\end{array}$ & 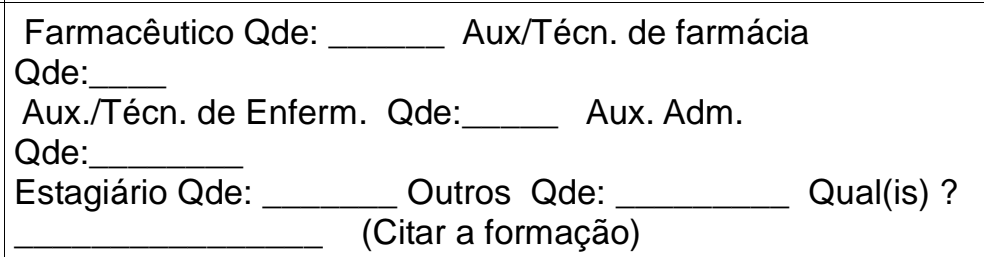 \\
\hline $\begin{array}{l}\text { № DE PROFISSIONAIS } \\
\text { ASSISTÊNCIA FARMACÊUTICA } \\
\text { COM PÓS GRADUAÇÃO NA } \\
\text { ÁREA DE ASSIST. } \\
\text { FARMACÊUTICA }\end{array}$ & $\begin{array}{ll}\text { Especialização Qde: } & \text { Mestrado } \\
\text { Doutorado Qde:__ Outros }\end{array}$ \\
\hline $\begin{array}{l}\text { № DE PROFISSIONAIS DA } \\
\text { ASSISTÊNCIA FARMACÊUTICA } \\
\text { COM PÓS GRADUAÇÃO EM } \\
\text { OUTRAS ÁREAS }\end{array}$ & \begin{tabular}{|ll} 
Especialização Qde: & Mestrado \\
Doutorado Qde: & Outros
\end{tabular} \\
\hline
\end{tabular}

TIPO DE VÍNCULO/FORMA DE CONTRATAÇÃO DOS PROFISSIONAIS DA AF QUE ATUAM NO PONTO DE ATENÇÃO À SAÚDE

\begin{tabular}{|c|c|c|c|c|c|c|c|}
\hline \multirow{5}{*}{$\begin{array}{l}\text { TIPO DE } \\
\text { VÍNCULO DOS } \\
\text { PROFISSIONA } \\
\text { IS QUE } \\
\text { ATUAM NA AF } \\
\text { POR } \\
\text { CATEGORIA }\end{array}$} & $\begin{array}{l}\text { VÍNCULO/CATEGORIA } \\
\text { PROFISSIONAL }\end{array}$ & $\begin{array}{l}\text { COMISSIO } \\
\text { NADO }\end{array}$ & $\begin{array}{l}\text { CONCUR } \\
\text { SADO }\end{array}$ & $\begin{array}{l}\text { CONTRA } \\
\text { TADO }\end{array}$ & $\begin{array}{c}\text { CEDIDO } \\
\text { POR } \\
\text { OUTRO } \\
\text { ORGÃO }\end{array}$ & $\begin{array}{c}\text { TERC } \\
\text { ERIZA } \\
\text { DO }\end{array}$ & $\begin{array}{c}\text { OUTROS } \\
\left(\begin{array}{l}(!)\end{array}\right.\end{array}$ \\
\hline & Farmacêutico & & & & & & \\
\hline & Aux/Técn de farmácia & & & & & & \\
\hline & $\begin{array}{l}\text { Aux/Técn de } \\
\text { Enfermagem }\end{array}$ & & & & & & \\
\hline & Aux. administrativo & & & & & & \\
\hline
\end{tabular}




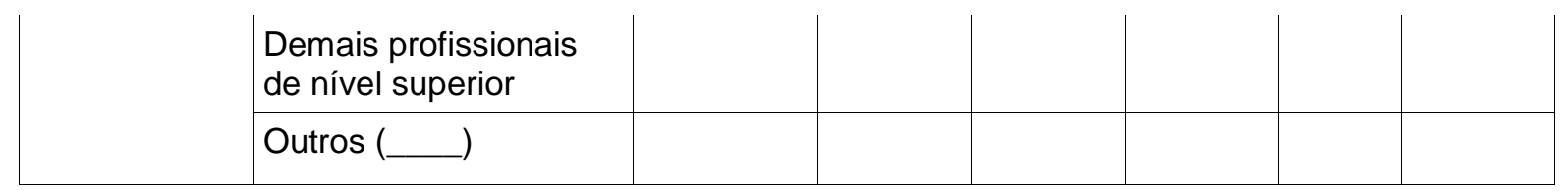

Responsável pelo Ponto de Atenção e/ou Apoio Terapêutico

\section{Data} l

Horário do Início da entrevista _ Horário de Termino da entrevista

\begin{tabular}{|c|c|c|}
\hline \multicolumn{3}{|c|}{ Variável: Informações e Educação em Saúde. } \\
\hline 1 & $\begin{array}{l}\text { D1P12 - Existe material informativo sobre } \\
\text { medicamentos para ser disponibilizado aos } \\
\text { usuários no estabelecimento de saúde? }\end{array}$ & $\begin{array}{l}\text { ( ) Sim. Qual tema? } \\
\text { ( ) Não } \\
\text { ( ) Não Sei }\end{array}$ \\
\hline 2 & $\begin{array}{l}\text { D1P13 - Há disponibilidade de Informação } \\
\text { visível ao usuário sobre os locais de } \\
\text { dispensação de medicamentos padronizados? }\end{array}$ & $\begin{array}{l}\text { ( ) Sim. Qual a forma? } \\
\text { (na página eletrônica do Município, cartaz, } \\
\text { panfleto ou outras formas) } \\
\text { ( ) Não } \\
\text { ( ) Não sei }\end{array}$ \\
\hline 3 & $\begin{array}{l}\text { D1P14 - O município (ponto) disponibiliza a lista } \\
\text { de medicamentos padronizados (e suas } \\
\text { atualizações) impressa nos consultórios dos } \\
\text { prescritores? }\end{array}$ & $\begin{array}{l}\text { () Sim } \\
\text { () Não } \\
\text { ( ) Não sei }\end{array}$ \\
\hline 4 & $\begin{array}{l}\text { D3P18 - Existe algum usuário deste serviço que } \\
\text { faz uso de medicamentos do componente } \\
\text { especializado da Assistência Farmacêutica? }\end{array}$ & $\begin{array}{l}\text { ( ) Sim } \\
\text { () Não } \\
\text { () ) Não sei }\end{array}$ \\
\hline & $\begin{array}{l}\text { D3P19 - É informado ao usuário de como ter } \\
\text { acesso aos medicamentos do componente } \\
\text { especializado? }\end{array}$ & $\begin{array}{l}\text { () Sim. Por quem? } \\
\text { () Farmacêutico } \\
\text { () Técnico/Auxiliar de Farmácia } \\
\text { () Enfermeiro } \\
\text { () Médico } \\
\text { () Assistente Social } \\
\text { () Agente Comunitário de Saúde } \\
\text { () Técnico/Auxiliar em Enfermagem } \\
\text { () Auxiliar Administrativo } \\
\text { () Outros: } \\
\text { () Não } \\
\text { () Não sei }\end{array}$ \\
\hline & $\begin{array}{l}\text { D3P20 - Como o usuário é informado sobre } \\
\text { acesso aos medicamentos do componente } \\
\text { especializado? }\end{array}$ & $\begin{array}{l}\text { () Verbalmente } \\
\text { () Panfleto } \\
\text { () Cartaz } \\
\text { () Protocolo clínico impresso } \\
\text { () Internet } \\
\text { () Outros } \\
\text { () Não sei } \\
\text { () Não se aplica }\end{array}$ \\
\hline & $\begin{array}{l}\text { D3P21 - A equipe de Saúde realiza atividades } \\
\text { de educação em saúde que aborde o uso de } \\
\text { plantas medicinais e/ou fitoterápicos? } \\
\text { *se sim responder a D3P22 }\end{array}$ & $\begin{array}{l}\text { ( ) Sim } \\
\text { ( ) Não } \\
\text { ( ) Não sei }\end{array}$ \\
\hline & $\begin{array}{l}\text { D3P22 - Quem realiza atividades de educação } \\
\text { em saúde abordando o uso de plantas } \\
\text { medicinais e/ou fitoterápicos? } \\
{ }^{*} \text { responder se informado sim na D3P21 }\end{array}$ & $\begin{array}{l}\text { () Farmacêuticos } \\
\text { () Médicos } \\
\text { () Enfermeiro } \\
\text { () Técnico/Auxiliar de Farmácia } \\
\text { () Técnico/Auxiliar de Enfermagem } \\
\text { () Agente Comunitário de Saúde } \\
\text { () Outros: } \\
\text { () Não sei }\end{array}$ \\
\hline
\end{tabular}


( ) Não se aplica

\begin{tabular}{l} 
Variáveis: Educação permanente; Suporte técnico para a equipe de saúde; Informação e \\
Educação em Saúde. \\
\hline
\end{tabular}

\begin{tabular}{|l|l|}
\hline \multicolumn{2}{|l|}{ Variável: Programação de Medicamentos. } \\
\hline $\begin{array}{l}\text { D1P28 - Existe um cronograma de envio de } \\
\text { informações pelas Unidades para a }\end{array}$ & $\begin{array}{l}\text { ( ) Sim } \\
\text { programação de compras? }\end{array}$ \\
\hline $\begin{array}{ll}\text { D1P29 - Existe cronograma de envio do pedido } \\
\text { para abastecimento das unidades para a CAF? }\end{array}$ & ( ) Sim \\
Vai para a variável Abastecimento & ( ) Não \\
\hline
\end{tabular}

\begin{tabular}{|l|l|l|}
\hline \multicolumn{2}{|l|}{ Variável: Integração da Assistência Farmacêutica com outras áreas técnicas. } \\
\hline \multicolumn{2}{|l}{} & ( ) Sim \\
& () semanal \\
() quinzenal \\
Farmacêutica se reúnem com a equipe & () Mensalmente \\
multiprofissional para discutir processos de & () Bimensalmente \\
trabalho? & () Trimestralmente \\
& () Semestralmente \\
& () Anualmente \\
& () eventualmente (quando necessário) \\
& () Não \\
& () Não sei
\end{tabular}

\begin{tabular}{|c|c|}
\hline \multicolumn{2}{|l|}{ Variável: Estrutura. } \\
\hline $\begin{array}{l}\text { D2P1 - O estabelecimento possui Licença para } \\
\text { Funcionamento vigente expedida pelo órgão de } \\
\text { Vigilância Sanitária local? }\end{array}$ & $\begin{array}{l}\text { ( ) Sim, não fixado em local visível } \\
\text { ( ) Sim, fixado em local visível } \\
\text { ( ) Não } \\
\text { ( ) Não sei }\end{array}$ \\
\hline $\begin{array}{l}\text { D2P2 - O estabelecimento possui Certidão de } \\
\text { Regularidade Técnica vigente, emitida pelo } \\
\text { Conselho Regional de Farmácia da respectiva } \\
\text { jurisdição? }\end{array}$ & $\begin{array}{l}\text { ( ) Sim, não fixado em local visível } \\
\text { ( ) Sim, fixado em local visível } \\
\text { ( ) Não } \\
\text { () Não sei }\end{array}$ \\
\hline $\begin{array}{l}\text { D2P4 - O estabelecimento possui licença do } \\
\text { Corpo de Bombeiros? } \\
\text { * também para o secretário de saúde }\end{array}$ & $\begin{array}{l}\text { ( ) Sim } \\
\text { ( ) Não } \\
\text { () Não sei }\end{array}$ \\
\hline $\begin{array}{l}\text { D2P31 - O estabelecimento possui extintor de } \\
\text { incêndio? } \\
\text { * }{ }^{1 \text { a }} \text { questão sobre o tema, apenas para } \\
\text { entrevista }\end{array}$ & $\begin{array}{l}\text { ( ) Sim } \\
\text { ( ) Não } \\
\text { ( ) Não sei }\end{array}$ \\
\hline $\begin{array}{l}\text { D2P7 - Existe um espaço específico para o } \\
\text { armazenamento de medicamentos sujeitos a } \\
\text { controle especial? }\end{array}$ & $\begin{array}{l}\text { ( ) Sim } \\
\text { ( ) Não } \\
\text { ( ) Não se aplica }\end{array}$ \\
\hline
\end{tabular}


Variáveis: Estrutura; Procedimentos; Recursos Humanos.

\begin{tabular}{l|l} 
D2P5 - A equipe recebeu treinamento para & ( ) Sim \\
utilizar os equipamentos contra incêndio? & ( ) Não \\
\end{tabular}

\begin{tabular}{|c|c|}
\hline \multicolumn{2}{|l|}{ Variáveis: Estrutura; Procedimentos. } \\
\hline $\begin{array}{l}\text { D2P9 - É realizado o registro diário de } \\
\text { temperatura máxima e minima, e umidade } \\
\text { relativa do ambiente ? } \\
\text { Padrões exigidos: } \\
\text { Umidade relativa: deve se manter ente } 40 \text { e } \\
70 \% \\
\text { Temperatura de conservação - segundo a } \\
\text { Farmacopéia Americana (USP): } \\
\text { Ambiente - temperatura entre } 15^{\circ} \text { e } 30^{\circ} \mathrm{C} \text { - com } \\
\text { controle mediante termostato. Recomenda-se } \\
\text { temperatura próxima a } 20^{\circ} \mathrm{C} \text {. }\end{array}$ & $\begin{array}{l}\text { Temperatura } \\
\text { ( ) Sim } \\
\text { () Não } \\
\text { ( ) Não sei } \\
\text { Umidade } \\
\text { ( ) Sim } \\
\text { () Não } \\
\text { ( ) Não sei }\end{array}$ \\
\hline $\begin{array}{l}\text { D2P13 - Existe refrigerador ou câmara fria para } \\
\text { o armazenamento de medicamentos sensíveis à } \\
\text { temperatura? }\end{array}$ & $\begin{array}{l}\text { ( ) Sim, exclusivo para medicamentos } \\
\text { ( ) Sim, junto com a vacina } \\
\text { ( ) Sim, com alimentos e outros produtos } \\
\text { ( ) Não } \\
\text { ( ) Não se aplica } \\
\text { Se Sim, é realizado o registro e controle } \\
\text { diário de temperatura? } \\
\text { () Sim } \\
\text { ( ) Não } \\
\text { ( )Não sei }\end{array}$ \\
\hline $\begin{array}{l}\text { D2P27 - Existe no estabelecimento um local } \\
\text { específico para a deposição de resíduos de } \\
\text { medicamentos (embalagens, sobras, } \\
\text { medicamentos vencidos/fora da conformidade) } \\
\text { até que sejam recolhidos? }\end{array}$ & $\begin{array}{l}\text { ( ) Sim } \\
\text { () Não } \\
\text { () Não sei }\end{array}$ \\
\hline
\end{tabular}

\begin{tabular}{|c|c|}
\hline \multicolumn{2}{|c|}{ Variáveis: Suporte técnico para a equipe de saúde; Estrutura. } \\
\hline D2P14 - O estabelecimento possui: & $\begin{array}{l}\text { Telefone } \\
\text { ( ) Sim. Quantos? } \\
\text { ( ) Não } \\
\text { Fax } \\
\text { ( ) Sim. Quantos? } \\
\text { ( ) Não } \\
\text { Computadores } \\
\text { ( ) Sim. Quantos? } \\
\text { ( ) Não } \\
\text { Impressora } \\
\text { ( ) Sim. Quantos? } \\
\text { ( ) Não } \\
\text { Internet } \\
\text { ( ) Sim. Quantos pontos de acesso? } \\
\text { () Não }\end{array}$ \\
\hline
\end{tabular}




\begin{tabular}{|l|l|}
\hline \multirow{5}{*}{} & $\begin{array}{l}\text { () Outros meios de comunicação (ex. rádio, } \\
\text { telefone público). Qual(is) }\end{array}$ \\
\hline Telefone \\
() Sim. Quantos? \\
() Não, com acesso no mesmo \\
estabelecimento \\
() Não \\
Fax \\
() Sim. Quantos? \\
() Não, com acesso no mesmo \\
estabelecimento \\
() Não \\
D2P15-A farmácia possui: \\
Computadores \\
() Sim. Quantos? \\
() Não, com acesso no mesmo \\
estabelecimento \\
() Não \\
Impressora \\
() Sim. Quantos? \\
() Não, com acesso no mesmo \\
estabelecimento \\
() Não \\
Internet \\
() Sim. Quantos pontos de acesso? \\
() Não, com acesso no mesmo \\
estabelecimento \\
() Não \\
\hline
\end{tabular}

\begin{tabular}{|c|c|}
\hline \multicolumn{2}{|l|}{ Variável: Suporte técnico para a equipe de saúde. } \\
\hline $\begin{array}{l}\text { D2P17 - A lista padronizada de medicamentos é } \\
\text { disponibilizada aos profissionais? } \\
{ }^{*} \text { antes da D1P14 }\end{array}$ & $\begin{array}{l}\text { () } \operatorname{Sim} \\
\text { ( ) Não }\end{array}$ \\
\hline $\begin{array}{l}\text { D3P12 - É utilizada alguma fonte de informação } \\
\text { sobre medicamentos pela equipe de saúde? }\end{array}$ & $\begin{array}{l}\text { ( ) Sim. Qual(is)? } \\
\text { ( ) Portal Saúde Baseada em Evidências } \\
\text { ( ) Centro de Informação sobre Medicamento } \\
\text { / Serviço de informação sobre medicamento } \\
\text { (CIM/MIM) } \\
\text { ( ) Formulário Terapêutico Nacional } \\
\text { ( ) Dicionário de Especialidade farmacêuticas } \\
\text { (DEF) } \\
\text { ( ) Bula dos medicamentos } \\
\text { ( ) Internet } \\
\text { ( ) Aplicativo de celular } \\
\text { () Outros: } \\
\text { () Não } \\
\text { () Não sei }\end{array}$ \\
\hline
\end{tabular}

\section{Variáveis: Seleção de medicamentos; Procedimentos.}

D2P18 - Há um formulário disponível para a solicitação de inclusão/exclusão de medicamentos na lista padronizada?
( ) $\operatorname{Sim}$

( ) Não

() Não sei 


\begin{tabular}{|c|c|}
\hline \multicolumn{2}{|c|}{ Variáveis: Distribuição de medicamentos; Procedimentos. } \\
\hline $\begin{array}{l}\text { D2P19 - Para qual(is) atividade(s) existe } \\
\text { procedimento operacional padrão (POP)? }\end{array}$ & $\begin{array}{l}\text { () Recepção de medicamentos e insumos } \\
\text { () Armazenamento de medicamentos e } \\
\text { insumos } \\
\text { () Dispensação de medicamentos } \\
\text { () Controle de temperatura e umidade } \\
\text { () Controle de estoque } \\
\text { () Limpeza } \\
\text { () Fluxo de abastecimento } \\
\text { () Plano de gerenciamento de resíduos de } \\
\text { serviços de saúde (PGRSS) } \\
\text { () Outros: } \\
\text { () Não possui }\end{array}$ \\
\hline
\end{tabular}

\begin{tabular}{|c|c|}
\hline \multicolumn{2}{|l|}{ Variável: Procedimentos. } \\
\hline $\begin{array}{l}\text { D2P20 - Existe registro diário de entrada e } \\
\text { saída de medicamentos no estabelecimento? }\end{array}$ & $\begin{array}{l}\text { ( ) Sim, Hórus } \\
\text { () Sim, sistema informatizado próprio, } \\
\text { desenvolvido pelo município } \\
\text { ( ) Sim, sistema informatizado terceirizado } \\
\text { () Sim, planilha de Excel } \\
\text { () Sim, ficha de prateleira } \\
\text { () Sim, manual } \\
\text { () Sim. } \\
\text { Outro? } \\
\text { () Não } \\
\text { ( ) Não sei }\end{array}$ \\
\hline $\begin{array}{l}\text { D2P21 - O inventário (balanço) dos } \\
\text { medicamentos armazenados no } \\
\text { estabelecimento é feito: }\end{array}$ & $\begin{array}{l}\text { Medicamentos sujeitos a controle especial: } \\
\text { () Semanalmente } \\
\text { () Quinzenalmente } \\
\text { () Mensalmente } \\
\text { () Trimestralmente } \\
\text { () Semestralmente } \\
\text { () Anualmente } \\
\text { () Não é feito } \\
\text { () Não há medicamentos sujeitos a controle } \\
\text { especial } \\
\text { Outros medicamentos: } \\
\text { () Semanalmente } \\
\text { () Quinzenalmente } \\
\text { () Mensalmente } \\
\text { () Trimestralmente } \\
\text { () Semestralmente } \\
\text { () Anualmente } \\
\text { () Não é feito } \\
\text { () Possui apenas medicamentos sujeitos a } \\
\text { controle especial }\end{array}$ \\
\hline $\begin{array}{l}\text { D2P28 - Existe um serviço de recolhimento de } \\
\text { resíduos de medicamentos (embalagens, } \\
\text { sobras, medicamentos inapropriados para o } \\
\text { consumo) do estabelecimento? } \\
\text { * próxima a pergunta D2P27 }\end{array}$ & $\begin{array}{l}\text { ( ) Sim, por? } \\
\text { ( ) empresa especializada } \\
\text { ( ) coleta de lixo comum } \\
\text { () Não } \\
\text { ( ) Não sei }\end{array}$ \\
\hline
\end{tabular}

\begin{tabular}{|l|l|l|}
\hline \multicolumn{2}{|l|}{ Variáveis: Abastecimento de medicamentos e insumos; Programação de medicamentos. } \\
\hline $\begin{array}{l}\text { D2P22 - Existem períodos de desabastecimento } \\
\text { de medicamentos no estabelecimento? }\end{array}$ & $\begin{array}{l}\text { () ) Quase sempre } \\
\text { () Âs vezes }\end{array}$ \\
\hline
\end{tabular}




\begin{tabular}{|l|l|l|}
\hline & $\begin{array}{l}\text { () Raramente } \\
\text { () Não ocorre }\end{array}$ \\
\hline $\begin{array}{l}\text { D2P46-Qual o total de medicamentos } \\
\text { padronizados no estabelecimento? }\end{array}$ & Total de medicamentos padronizados: \\
\hline $\begin{array}{l}\text { D2P50- Quantos itens estão faltando no } \\
\text { momento, em relação à lista padronizada? }\end{array}$ & No de medicamentos em falta: \\
\hline $\begin{array}{l}\text { D2P23 - Caso ocorra desabastecimento, } \\
\text { qual(is) o(s) motivo(s)? }\end{array}$ & $\begin{array}{l}\text { () Problemas do setor de compras } \\
\text { () Problemas do mercado farmacêutico } \\
\text { () Problemas de repasses de medicamentos } \\
\text { nas instâncias do SUS } \\
\text { () ) Atraso na distribuição para as Unidades } \\
\text { () Atraso na entrega do } \\
\text { distribuidor/fornecedor } \\
\text { () Outro: }\end{array}$ \\
\hline
\end{tabular}

\begin{tabular}{|c|c|}
\hline $\begin{array}{l}\text { D2P24 - Qual o procedimento adotado com o } \\
\text { usuário, quando falta algum medicamento? }\end{array}$ & $\begin{array}{l}\text { ( ) Encaminha o usuário para outra unidade } \\
\text { () Encaminha para o Programa Farmácia } \\
\text { Popular } \\
\text { () Encaminha para uma farmácia comercial } \\
\text { () Registra o contato do usuário para avisar } \\
\text { quando o medicamento chegar } \\
\text { () Solicita o retorno posteriormente } \\
\text { () Nenhum procedimento é adotado } \\
\text { () Outro }\end{array}$ \\
\hline $\begin{array}{l}\text { D2P25 - Quando há excesso de medicamentos } \\
\text { no estoque, qual o procedimento adotado? }\end{array}$ & $\begin{array}{l}\text { () Ajuste na programação } \\
\text { ( ) Redistribuição entre Unidades de Saúde } \\
\text { () Devolução para a Central de } \\
\text { Abastecimento Farmacêutico (CAF) } \\
\text { () Doação } \\
\text { () Realiza troca com outros serviços do } \\
\text { município } \\
\text { ( ) Empréstimo dentro da rede (outros } \\
\text { municípios/Estado) } \\
\text { () Perde-se o que sobrou } \\
\text { () Não há excesso } \\
\text { () Outro: } \\
\text { () Não sei }\end{array}$ \\
\hline
\end{tabular}

\begin{tabular}{|l|l|l|}
\hline \multicolumn{2}{|l|}{ Variável: Planejamento das ações da Assistência Farmacêutica. } \\
\hline $\begin{array}{l}\text { D2P38 - Existem amostras grátis no } \\
\text { estabelecimento? }\end{array}$ & $\begin{array}{l}\text { ( ) Sim, na farmácia } \\
\text { () Sim, no consultório do prescritor }\end{array}$ \\
\hline () Sim, outro local: \\
\hline $\begin{array}{l}\text { D2P39 - O estabelecimento recebe visita de } \\
\text { representante/propagandista da }\end{array}$ & () Não sei \\
indústria/distribuidora de medicamentos? & () Sim \\
& () Não \\
\end{tabular}

\footnotetext{
Variáveis: Planejamento das ações da Assistência Farmacêutica; Procedimentos.
D2P40 - Há serviço de entrega de medicamentos em casa?




\begin{tabular}{|c|c|}
\hline & $\begin{array}{l}\text { ( ) Sim, não formalizado } \\
\text { ( ) Não } \\
\text { ( ) Não sei }\end{array}$ \\
\hline $\begin{array}{l}\text { D2P41 - Caso realize serviço de entrega de } \\
\text { medicamentos em casa, } \\
\text { Qual o critério de inclusão de usuário neste } \\
\text { serviço? }\end{array}$ & $\begin{array}{l}\text { ( ) Acamados } \\
\text { ( ) Idosos sem cuidadores/ } \\
\text { responsáveis/dificuldade de locomoção } \\
\text { ( ) Cuidados paliativos } \\
\text { ( ) Usuários de medicamentos de uso } \\
\text { contínuo } \\
\text { () Localidade de difícil acesso } \\
\text { () Usuários do serviço de Saúde Mental } \\
\text { () Usuário com deficiência } \\
\text { () Outros: } \\
\text { () Não sei }\end{array}$ \\
\hline $\begin{array}{l}\text { D2P42 - Caso realize serviço de entrega de } \\
\text { medicamentos em casa, } \\
\text { Quais os medicamentos que são entregues? }\end{array}$ & $\begin{array}{l}\text { () Medicamentos do Componente Básico da } \\
\text { Assistência Farmacêutica } \\
\text { () Medicamentos do Componente } \\
\text { Especializado da Assistência Farmacêutica } \\
\text { () Medicamentos do Componente Estratégico } \\
\text { da Assistência Farmacêutica } \\
\text { ( ) Medicamentos de uso hospitalar } \\
\text { () Outros: } \\
\text { () Não sei }\end{array}$ \\
\hline $\begin{array}{l}\text { D3P62 - Qual o meio de transporte utilizado } \\
\text { para a entrega de medicamentos em casa? } \\
\text { Caso realize serviço de entrega de } \\
\text { medicamentos em casa }\end{array}$ & $\begin{array}{l}\text { () A pé } \\
\text { () Motocicleta } \\
\text { () Carro utilitário com baú (Ex.: picape) } \\
\text { () Carro de passeio } \\
\text { () Barco } \\
\text { () Outros: } \\
\text { () Não sei }\end{array}$ \\
\hline $\begin{array}{l}\text { D2P43 - Caso realize serviço de entrega de } \\
\text { medicamentos em casa, } \\
\text { Os profissionais envolvidos receberam } \\
\text { capacitação? }\end{array}$ & $\begin{array}{l}\text { () Sim. Por quem: } \\
\text { () Profissionais da Assistência Farmacêutia } \\
\text { () Profissionais da Equipe de Saúde } \\
\text { () Outros } \\
\text { () Não receberam } \\
\text { () Não sei }\end{array}$ \\
\hline $\begin{array}{l}\text { D2P44 - Caso realize serviço de entrega de } \\
\text { medicamentos em casa, } \\
\text { Como é feito o armazenamento dos } \\
\text { medicamentos no veículo? }\end{array}$ & $\begin{array}{l}\text { () Sacola plástica } \\
\text { () Caixa de papelão } \\
\text { () Maleta } \\
\text { () Recepiente térmico (isopor ou semelhante) } \\
\text { () Outros } \\
\text { () Não sei }\end{array}$ \\
\hline $\begin{array}{l}\text { D2P45 - Caso realize serviço de entrega de } \\
\text { medicamentos em casa, } \\
\text { O controle de temperatura durante o transporte } \\
\text { é realizado? }\end{array}$ & $\begin{array}{l}\text { ( ) Sim, Como? } \\
\text { ( ) Não realiza } \\
\text { () Não sei }\end{array}$ \\
\hline $\begin{array}{l}\text { D2P47 - Caso realize serviço de entrega de } \\
\text { medicamentos em casa, } \\
\text { Como é realizado o acompanhamento destes } \\
\text { usuários? }\end{array}$ & $\begin{array}{l}\text { () Profissionais do NASF } \\
\text { () Visita Domiciliar pela ESF } \\
\text { () Profissionais da Unidades de saúde/CAPS } \\
\text { () Programa Melhor em Casa } \\
\text { () Outros } \\
\text { () Não realiza } \\
\text { () Não sei }\end{array}$ \\
\hline
\end{tabular}

Variável: Dispensação de medicamentos. 


\begin{tabular}{|c|c|}
\hline aos usuários? & $\begin{array}{l}\text { OPÇÕES DE MENU: ( ) Sempre, ( )Quase } \\
\text { sempre, } \\
\text { ( ) Âs vezes, ( ) Raramente, ( ) Nunca, ( ) Não } \\
\text { sei } \\
\text { ( )Enfermeiro } \\
\text { OPÇÕES DE MENU: ( ) Sempre, ( )Quase } \\
\text { sempre, } \\
\text { ( ) Âs vezes, ( ) Raramente, ( ) Nunca, ( ) Não } \\
\text { sei } \\
\text { ( ) Auxiliar/Técnico de Farmácia } \\
\text { OPÇÕES DE MENU: ( ) Sempre, ( )Quase } \\
\text { sempre, } \\
\text { ( ) Âs vezes, ( ) Raramente, ( ) Nunca, ( ) Não } \\
\text { sei } \\
\text { ( ) Auxiliar/Técnico de Enfermagem } \\
\text { OPÇÕES DE MENU: ( ) Sempre, ( )Quase } \\
\text { sempre, } \\
\text { ( ) Âs vezes, ( ) Raramente, ( ) Nunca, ( ) Não } \\
\text { sei } \\
\text { ( ) Agente Comunitário de Saúde } \\
\text { OPÇÕES DE MENU: ( ) Sempre, ( )Quase } \\
\text { sempre, } \\
\text { ( ) Âs vezes, ( ) Raramente, ( ) Nunca, ( ) Não } \\
\text { sei } \\
\text { () Auxiliar administrativo } \\
\text { OPÇÕES DE MENU: ( ) Sempre, ( )Quase } \\
\text { sempre, } \\
\text { ( ) Às vezes, ( ) Raramente, ( ) Nunca, ( ) Não } \\
\text { sei } \\
\text { ( ) Outro Profissional. Formação? } \\
\text { OPÇÕES DE MENU: ( ) Sempre, ( )Quase } \\
\text { sempre, } \\
\text { ( ) Às vezes, ( ) Raramente, ( ) Nunca, ( ) Não } \\
\text { sei } \\
\text { ( ) Não sei }\end{array}$ \\
\hline $\begin{array}{l}\text { D3P2 - No momento da entrega do } \\
\text { medicamento o profissional fornece algum tipo } \\
\text { de orientação ao usuário? }\end{array}$ & $\begin{array}{l}\text { ( ) Farmacêutico } \\
\text { OPÇÕES DE MENU: ( ) Sempre, ( )Quase } \\
\text { sempre, } \\
\text { ( ) Às vezes, ( ) Raramente, ( ) Nunca, ( ) Não } \\
\text { sei } \\
\text { ( )Enfermeiro } \\
\text { OPÇÕES DE MENU: ( ) Sempre, ( )Quase } \\
\text { sempre, } \\
\text { ( ) Às vezes, ( ) Raramente, ( ) Nunca, ( ) Não } \\
\text { sei } \\
\text { ( ) Auxiliar/Técnico de Farmácia } \\
\text { OPÇÕES DE MENU: ( ) Sempre, ( )Quase } \\
\text { sempre, } \\
\text { ( ) Às vezes, ( ) Raramente, ( ) Nunca, ( ) Não } \\
\text { sei } \\
\text { ( ) Auxiliar/Técnico de Enfermagem } \\
\text { OPÇÕES DE MENU: ( ) Sempre, ( )Quase } \\
\text { sempre, } \\
\text { ( ) Às vezes, ( ) Raramente, ( ) Nunca, ( ) Não } \\
\text { sei } \\
\text { ( ) Agente Comunitário de Saúde } \\
\text { OPÇÕES DE MENU: ( ) Sempre, ( )Quase } \\
\text { sempre, } \\
\text { ( ) Às vezes, ( ) Raramente, ( ) Nunca, ( ) Não }\end{array}$ \\
\hline
\end{tabular}




\begin{tabular}{|c|c|}
\hline & $\begin{array}{l}\text { sei } \\
\text { ( ) Auxiliar administrativo } \\
\text { OPÇÕES DE MENU: ( ) Sempre, ( )Quase } \\
\text { sempre, } \\
\text { ( ) Às vezes, ( ) Raramente, ( ) Nunca, ( ) Não } \\
\text { sei } \\
\text { ( ) Outro Profissional. Formação? } \\
\text { OPÇÕES DE MENU: ( ) Sempre, ( )Quase } \\
\text { sempre, } \\
\text { ( ) Âs vezes, ( ) Raramente, ( ) Nunca, ( ) Não } \\
\text { sei } \\
\text { ( ) Não sei }\end{array}$ \\
\hline $\begin{array}{l}\text { D3P23 - É realizado agendamento* da } \\
\text { dispensação de medicamentos de uso contínuo } \\
\text { (tratamento de condições crônicas) em algum } \\
\text { estabelecimento? } \\
\text { ^Entendendo agendamento como informação } \\
\text { registrada ao usuário e ao estabelecimento. }\end{array}$ & $\begin{array}{l}\text { ( ) Sim. Qual a forma? } \\
\text { ( ) Manual, } \\
\text { ( ) Planilha do Excel, } \\
\text { ( ) Software informatizado (ex.: Hórus) } \\
\text { ( ) Outro: } \\
\text { ( ) Não } \\
\text { ( ) Não sei. }\end{array}$ \\
\hline $\begin{array}{l}\text { D3P24 - Qual procedimento adotado quando é } \\
\text { identificado o não comparecimento do usuário } \\
\text { na retirada de medicamentos? }\end{array}$ & $\begin{array}{l}\text { ( ) Busca ativa pela equipe da Assistência } \\
\text { Farmacêutica } \\
\text { ( ) Busca ativa pela equipe da Unidade de } \\
\text { Saúde de referência } \\
\text { ( ) Comunica-se com a equipe de Atenção } \\
\text { Primária à Saúde do usuário (Estratégia } \\
\text { Saúde da Família ou outro) } \\
\text { ( ) Aguarda o retorno do usuário } \\
\text { ( ) Retira o usuário do programa } \\
\text { ( ) Outros: } \\
\text { () Não sei } \\
\text { () Nenhum procedimento é realizado } \\
\text { ( ) Não é realizada a identificação }\end{array}$ \\
\hline D3P27 - São dispensados fitoterápicos? & $\begin{array}{l}\text { () Sim, (RENAME - 2012) } \\
\text { Quais: } \\
\text { ( )alcachofra (Cynara scolymus) } \\
\text { ( )aroeira (Schinus terebinthifolius) } \\
\text { ( )babosa (Aloe vera (L.) Burm. f.) } \\
\text { () )áscara-sagrada (Rhamnus purshiana) } \\
\text { ( )espinheira-santa (Maytenus officinalis } \\
\text { Mabb.) } \\
\text { ( )garra-do-diabo (Harpagophytum } \\
\text { procumbens) } \\
\text { ()guaco (Mikania glomerata) } \\
\text { ()hortelã (Mentha x piperita L.) } \\
\text { () isoflavona-de-soja (Glycine max) } \\
\text { ( )plantago (Plantago ovata Forssk.) } \\
\text { () unha-de-gato (Uncaria tomentosa) } \\
\text { ()salgueiro (Salix alba)) } \\
\text { () Sim. Outros } \\
\text { () Não( ) Não sei }\end{array}$ \\
\hline
\end{tabular}

Variável: Orientação Terapêutica/Saúde.

D3P4 - Os profissionais da Unidade de Saúde realizam atividades em grupo aos usuários sobre o uso de medicamentos?

( ) Sim. Qual(is) profissional(is):

( ) Farmacêutico

( ) Enfermeiro 


\begin{tabular}{|l|l|}
\hline & ( ) Médico \\
& ( ) Agente Comunitário de Saúde/ Agente \\
Comunitário de Endemias \\
() Técnico em Enfermagem \\
() Outros \\
() Não \\
() Não sei
\end{tabular}

\begin{tabular}{|l|l|l|}
\hline \multicolumn{2}{|l|}{ Variável: Seguimento Farmacoterapêutico. } \\
\hline $\begin{array}{l}\text { D3P5 - Este estabelecimento realiza } \\
\text { seguimento farmacoterapêutico? } \\
\text { *necessário discussão com Ondina devido a } \\
\text { terminologia do "documento secreto" }\end{array}$ & $\begin{array}{l}\text { ( ) Sim. Quem faz? } \\
\text { ( ) Farmacêutico } \\
\text { ( ) Enfermeiro } \\
\text { ( ) Médico } \\
\text { ( ) Outros } \\
\text { ( ) Não } \\
\text { ( ) Não sei }\end{array}$ \\
$\begin{array}{l}\text { D3P30 - Para quais grupos de usuários são } \\
\text { realizados o seguimento farmacoterapêutico? }\end{array}$ & $\begin{array}{l}\text { ( ) Hiperdia } \\
\text { ( ) Tuberculose }\end{array}$ \\
$\begin{array}{ll}\text { ( ) Asmaneniase } \\
\text { ( ) DST, AIDS }\end{array}$ \\
$\begin{array}{ll}\text { D3P6 - São utilizados Protocolos Clínicos no } \\
\text { seguimento farmacoterapêutico do usuário? }\end{array}$ & $\begin{array}{l}\text { ( ) Sim, qual(is)? } \\
\text { ( ) Não }\end{array}$ \\
\hline
\end{tabular}

\begin{tabular}{|l|l|l|}
\hline $\begin{array}{l}\text { D3P7 - Existe fluxo/procedimento para a } \\
\text { notificação de queixa e/ou evento adverso de } \\
\text { medicamento no Município? }\end{array}$ & $\begin{array}{l}\text { ( ) Sim Não } \\
\text { ( ) Não sei }\end{array}$ \\
\hline
\end{tabular}

\begin{tabular}{|c|c|}
\hline \multicolumn{2}{|l|}{ Variável: Farmacovigilância. } \\
\hline $\begin{array}{l}\text { D3P8 - Qual é o encaminhamento dado às } \\
\text { queixas técnicas e/ou eventos adversos a } \\
\text { medicamentos? }\end{array}$ & $\begin{array}{l}\text { ( ) Nenhum } \\
\text { ( ) Encaminhado para o nível central da } \\
\text { Assistência Farmacêutica } \\
\text { ( ) Sistema de notificações em vigilância } \\
\text { sanitária - NOTIVISA } \\
\text { ( ) Encaminhado para Vigilância em Saúde } \\
\text { municipal; } \\
\text { ( ) Encaminhado para outro setor. Qual? } \\
\text { ( ) Encaminhado para outro profissional. } \\
\text { Qual? } \\
\text { ( ) Não recebemos notificações de efeitos } \\
\text { adversos } \\
\text { ( ) Outros encaminhamentos } \\
\text { ( ) Não sei }\end{array}$ \\
\hline $\begin{array}{l}\text { D3P3 - É realizada a notificação de queixas } \\
\text { e/ou eventos adversos a medicamentos? }\end{array}$ & $\begin{array}{l}\text { ( ) Sim } \\
\text { ( ) Não } \\
\text { () Não sei }\end{array}$ \\
\hline $\begin{array}{l}\text { D3P9 - No último ano, qual o número de queixa } \\
\text { e/ou notificações de efeitos adversos foram } \\
\text { registrados? }\end{array}$ & $\begin{array}{l}\text { ( ) } 0 \text { ( ) } 1 \text { ( ) } 2 \text { ( ) } 3 \text { ( ) } 4 \text { ( ) } 5 \text { ( ) } 6 \text { ( ) } 7 \text { ( ) } 8 \text { ( ) } 9 \\
\text { ( ) } 10 \text { ( ) acima de 10: } \\
\text { () Não sei }\end{array}$ \\
\hline
\end{tabular}

\begin{tabular}{|c|c|}
\hline \multicolumn{2}{|c|}{ Variáveis: Suporte técnico para a equipe de saúde; Educação Permanente. } \\
\hline $\begin{array}{l}\text { D3P11 - Quantas atividades de capacitação } \\
\text { e/ou educação permanente PARA O USO } \\
\text { RACIONAL DE MEDICAMENTOS foram }\end{array}$ & 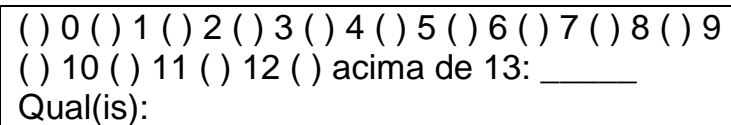 \\
\hline
\end{tabular}


realizadas pelo farmacêutico aos profissionais

da equipe de saúde, no último ano?

( ) Não sei

\begin{tabular}{|c|c|}
\hline \multicolumn{2}{|l|}{ Variável: Recursos Humanos. } \\
\hline $\begin{array}{l}\text { D3P13 - O farmacêutico realiza Visitas } \\
\text { Domiciliares? }\end{array}$ & $\begin{array}{l}\text { () ) Sim } \\
\text { () Não } \\
\text { () Não sei }\end{array}$ \\
\hline $\begin{array}{l}\text { D3P15 - Quais atividades o farmacêutico do } \\
\text { Núcleo de Apoio a Saúde da Família - NASF } \\
\text { realiza? }\end{array}$ & $\begin{array}{l}\text { Técnico-gerenciais: } \\
\text { ( ) seleção } \\
\text { ( ) programação } \\
\text { ( ) produção } \\
\text { ( ) aquisção } \\
\text { ( ) recebimento } \\
\text { ( ) armazenamento } \\
\text { ( ) distribuição } \\
\text { ( ) outros: } \\
\text { Técnico-assistenciais: } \\
\text { ( ) dispensação } \\
\text { () Matriciamento } \\
\text { ( ) Grupo Operativo de Educação em Saúde } \\
\text { ( ) Participação em construção de Projeto } \\
\text { Terapêutico Singular } \\
\text { ( ) Discussão de Casos } \\
\text { ( ) Seguimento Farmacoterapêutico } \\
\text { ( ) Orientação em Saúde } \\
\text { ( ) Outros: } \\
\text { ( ) Não se aplica. }\end{array}$ \\
\hline $\begin{array}{l}\text { D3P16 - Quais atividades o(s) farmacêutico(s) } \\
\text { realiza }(\mathrm{m}) \text { ? }\end{array}$ & $\begin{array}{l}\text { Técnico-gerenciais: } \\
\text { ( ) seleção } \\
\text { () programação } \\
\text { () produção } \\
\text { () aquição } \\
\text { ( ) recebimento } \\
\text { ( ) armazenamento } \\
\text { ( ) distribuição } \\
\text { ( ) outros: } \\
\text { Técnico-assistenciais: } \\
\text { ( ) dispensação } \\
\text { ( ) Matriciamento } \\
\text { ( ) Grupo Operativo de Educação em Saúde } \\
\text { ( ) Participação em construção de Projeto } \\
\text { Terapêutico Singular } \\
\text { ( ) Discussão de Casos } \\
\text { ( ) Seguimento Farmacoterapêutico } \\
\text { ( ) Orientação em Saúde } \\
\text { ( ) Outros: } \\
\text { ( ) Não se aplica. }\end{array}$ \\
\hline $\begin{array}{l}\text { D3P14 - Existe farmacêutico na equipe do } \\
\text { Núcleo de Apoio a Saúde da Família - NASF? }\end{array}$ & $\begin{array}{l}\text { ( ) Sim. Quantos? } \\
\text { () Não } \\
\text { () Não sei }\end{array}$ \\
\hline
\end{tabular}

Variável: Adesão ao tratamento medicamentoso.

D3P25 - Existe mecanismo para registrar a Não ( ) Sim. Qual(is)?

OPÇÕES DO MENU:

adesão dos usuários ao tratamento

( ) Ficha da Farmácia,

( ) Formulário específico de Adesão,

medicamentoso?

( ) Ficha de seguimento farmacoterapêutico,

( ) Prontuário manual,

() Prontuário eletrônico 


\begin{tabular}{|c|c|}
\hline & $\begin{array}{l}\text { ( ) Outro: } \\
\text { ( ) Não } \\
\text { ( ) Não sei }\end{array}$ \\
\hline $\begin{array}{l}\text { D3P26 - No caso de algum paciente apresentar } \\
\text { as dificuldades em utilizar seus medicamentos } \\
\text { de forma correta ou de compreender a terapia } \\
\text { que lhe foi prescrita, quais as estratégias } \\
\text { utilizadas para melhorar compreensão do } \\
\text { usuário sobre o uso de seus medicamentos? }\end{array}$ & $\begin{array}{l}\text { ( ) Utiliza métodos alternativos (pictogramas, } \\
\text { desenhos, cores e outros). } \\
\text { ( ) Encaminha ao profissional farmacêutico } \\
\text { ( ) Encaminha para o médico } \\
\text { ( ) Encaminha para o enfermeiro } \\
\text { ( ) Encaminha para o outros profissionais } \\
\text { ( ) Realiza contato com o Agente Comunitário } \\
\text { e } \\
\text { ( ) realiza contato com familiar e/ou cuidador } \\
\text { () Discussão de caso com o profissional } \\
\text { farmacêutico } \\
\text { ( ) Encaminha ao serviço de seguimento } \\
\text { farmacoterapêutico } \\
\text { ( ) Realiza contato com a equipe de atenção } \\
\text { básica (Estratégia de Saúde da Família, ou } \\
\text { outro) onde o usuário é cadastrado } \\
\text { ( ) Convite a participar de um grupo de } \\
\text { educação em saúde } \\
\text { ( ) Não realiza nenhum procedimento } \\
\text { ( ) Outro: } \\
\text { () Não sei }\end{array}$ \\
\hline
\end{tabular}

\section{Data: \\ Horário:}

Entrevistador - Observação Direta no Ponto de Atenção ou Apoio Terapêutico

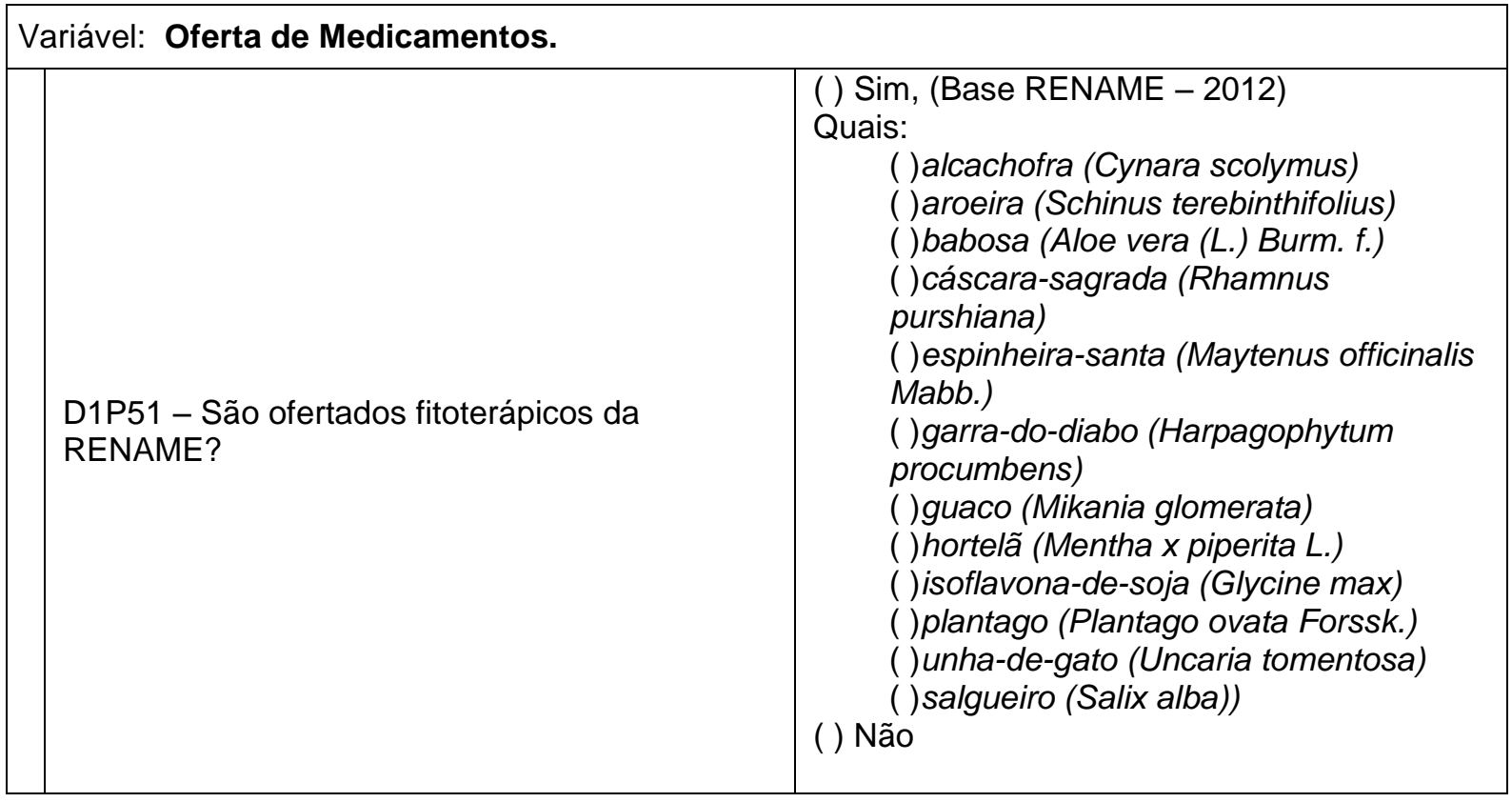

\begin{tabular}{|c|c|}
\hline \multicolumn{2}{|l|}{ Variável: Estrutura. } \\
\hline $\begin{array}{l}\text { D2P03 - A Licença de Funcionamento e a } \\
\text { Certidão de Regularidade estão afixadas em } \\
\text { local visível ao público? (Art. } 2^{\circ}, \$^{\circ} 1^{\circ} \text { da RDC } \\
\text { 44/09): }\end{array}$ & $\begin{array}{l}\text { () } \operatorname{Sim} \\
\text { ( ) Não }\end{array}$ \\
\hline $\begin{array}{l}\text { D2P6 - O espaço para o armazenamento de } \\
\text { medicamentos, no estabelecimento, é } \\
\text { adequada? }\end{array}$ & $\begin{array}{l}\text { ( ) Sim } \\
\text { ( ) Não } \\
\text { () Não existe um espaço específico para o } \\
\text { armazenamento de medicamentos. }\end{array}$ \\
\hline
\end{tabular}




\begin{tabular}{|c|c|}
\hline $\begin{array}{l}\text { D2P7 - Existe um espaço específico para o } \\
\text { armazenamento de medicamentos sujeitos a } \\
\text { controle especial? }\end{array}$ & $\begin{array}{l}\text { ( ) Sim } \\
\text { () Não } \\
\text { () Não sei }\end{array}$ \\
\hline $\begin{array}{l}\text { D2P10 - O ambiente está limpo, protegido da } \\
\text { ação direta da luz solar, umidade e calor, } \\
\text { ventilação adequada, de modo a preservar a } \\
\text { identidade e integridade, garantindo a qualidade } \\
\text { e segurança dos medicamentos? (Art. } 35, \S \S 1^{\circ}= \\
\text { e } 2^{\circ}, 36 \text { da RDC 44/09) }\end{array}$ & $\begin{array}{l}\text { Limpo? } \\
\text { ( ) Sim } \\
\text { ( ) Não } \\
\text { Protegido da ação direta da luz solar? } \\
\text { ( ) Sim } \\
\text { ( ) Não } \\
\text { Sem umidade? } \\
\text { ( ) Sim } \\
\text { ( ) Não } \\
\text { Protegido do calor? } \\
\text { ( ) Sim } \\
\text { ( ) Não } \\
\text { Com ventilação adequada? } \\
\text { ( ) Sim } \\
\text { ( ) Não }\end{array}$ \\
\hline $\begin{array}{l}\text { D2P11 - O ambiente destinado ao } \\
\text { armazenamento de medicamentos tem } \\
\text { capacidade suficiente para assegurar o } \\
\text { armazenamento ordenado das diversas } \\
\text { categorias de medicamentos? (Art. } 35, \S \S 1^{\circ}, 36 \\
\text { da RDC 44/09) }\end{array}$ & $\begin{array}{l}\text { () Sim } \\
\text { () Não }\end{array}$ \\
\hline $\begin{array}{l}\text { D2P12 - Os medicamentos estão armazenados } \\
\text { em gavetas, prateleiras ou suporte equivalente, } \\
\text { afastados do piso, parede e teto, a fim de } \\
\text { permitir sua fácil limpeza e inspeção ? (Art. } 35 \text {, } \\
\S \S 1^{\circ} \text { e } 2^{\circ}, 36 \text { da RDC } 44 / 09 \text { ) }\end{array}$ & $\begin{array}{l}\text { () Sim } \\
\text { () Não }\end{array}$ \\
\hline
\end{tabular}

\begin{tabular}{|l|l|}
\hline \multicolumn{2}{|l|}{ Variáveis: Estrutura; Procedimentos. } \\
\hline $\begin{array}{l}\text { D2P8 - A área de armazenagem de } \\
\text { medicamentos é climatizada, conforme } \\
\text { recomendação da Vigilância Sanitária? }\end{array}$ & $\begin{array}{l}\text { ( ) Sim } \\
\text { () Não }\end{array}$ \\
\hline $\begin{array}{ll}\text { D2P13 - Existe refrigerador ou câmara fria para } \\
\text { o armazenamento de medicamentos sensíveis à } \\
\text { temperatura? }\end{array}$ & $\begin{array}{l}\text { () Sim } \\
\text { () Não }\end{array}$ \\
() Não se aplica de acordo com a legislação sanitária? \\
$\begin{array}{ll}\text { Padrão exigido: } & \text { () Sim } \\
2 \text { a } 8^{\circ} \text { C } & \text { () Não } \\
& \text { Se Sim, é realizado o registro e controle } \\
\text { diário de temperatura? } & \text { () Sim }\end{array}$ \\
\hline
\end{tabular}

\begin{tabular}{|c|c|}
\hline \multicolumn{2}{|c|}{ Variáveis: Suporte técnico para a equipe de saúde; Estrutura. } \\
\hline D2P14 - O estabelecimento possui: & $\begin{array}{l}\text { Telefone } \\
\text { ( ) Sim. Quantos? } \\
\text { ( ) Não } \\
\text { Fax } \\
\text { ( ) Sim. Quantos? } \\
\text { ( ) Não } \\
\text { Computadores } \\
\text { ( ) Sim. Quantos? } \\
\text { ( ) Não } \\
\text { Impressora } \\
\text { ( ) Sim. Quantos? } \\
\text { ( ) Não } \\
\text { Internet }\end{array}$ \\
\hline
\end{tabular}




\begin{tabular}{|c|c|}
\hline & $\begin{array}{l}\text { () Sim. Quantos pontos de acesso? } \\
\text { ( ) Não }\end{array}$ \\
\hline D2P15 - A farmácia possui: & $\begin{array}{l}\text { Telefone } \\
\text { ( ) Sim. Quantos? } \\
\text { ( ) Não } \\
\text { Fax } \\
\text { ( ) Sim. Quantos? } \\
\text { ( ) Não } \\
\text { Computadores } \\
\text { ( ) Sim. Quantos? } \\
\text { ( ) Não } \\
\text { Impressora } \\
\text { () Sim. Quantos? } \\
\text { ( ) Não } \\
\text { Internet } \\
\text { ( ) Sim. Quantos pontos de acesso? } \\
\text { ( ) Não }\end{array}$ \\
\hline
\end{tabular}

Variável: Suporte técnico para a equipe de saúde.

D2P17 - A lista padronizada de medicamentos é ( ) Sim disponibilizada aos profissionais?

( ) Não

\begin{tabular}{|l|l|l|}
\hline \multicolumn{3}{|c|}{ Variável: Seleção de medicamentos; Procedimentos. } \\
\hline $\begin{array}{l}\text { D2P18 - Há um formulário disponível para a } \\
\text { solicitação de inclusão/exclusão de } \\
\text { medicamentos na lista padronizada de } \\
\text { medicamentos do Município? }\end{array}$ & ( ) Sim \\
\hline & () Não \\
\hline
\end{tabular}

Variável: Planejamento das ações da Assistência Farmacêutica.

\begin{tabular}{l|l} 
D2P38 - Existem amostras grátis no & ( ) Sim
\end{tabular}

\begin{tabular}{l|l} 
estabelecimento sendo entregue ao usuário? & ( ) Não \\
() Nãosei
\end{tabular}

Variável: Preço praticado.

D4P36 - Qual o valor unitário pago dos

Medicamentos do Componente Básico listados

a seguir no último processo licitatório?

\section{Variável: Dispensação de Medicamentos}

D3P31 - Ocorreu orientação durante a entrega dos medicamentos ao usuário?

( ) Sim

( ) Não

( ) Não foi observado durante a visita in locu

\section{Descritivos: \\ D- Dimensão \\ P- Pergunta}


ANEXO C - COMPROVANTE DE SUBMISSÃO A REVISTA SAÚDE EM DEBATE

\section{Saúde em Debate - Confirmação de recebimento de artigo}

Revista Saúde em Debate <revista@saudeemdebate.org.br>

22 de agosto de 2014

Responder a: Revista Saúde em Debate <revista@saudeemdebate.org.br>

Para: suetonioqueiroz@gmail.com

ÓRGÃO OFICIAL DO CEBES - Centro Brasileiro de Estudos de Saúde - ISSN 0103-1104

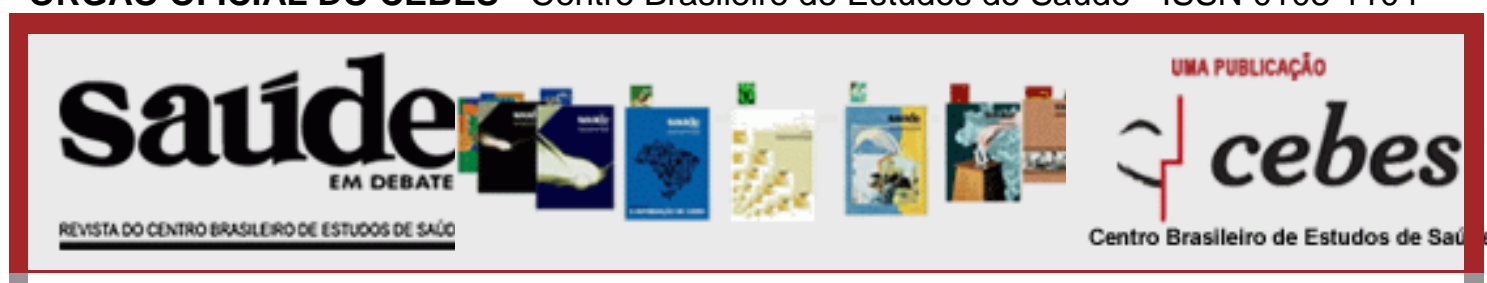

Seu trabalho A Assistência Farmacêutica nas Redes de Atenção à Saúde: 0 planejamento e os serviços no SUS foi recebido com sucesso.

Ele será encaminhado à Comissão Científica para análise e seleção.

Você poderá acompanhar o status da avaliação de seu trabalho através de sua área restrita, informando o login e a senha de acesso, que você cadastrou no momento de seu registro.

Atenciosamente,

Revista Saúde em Debate

Saúde em Debate - Revista do Centro Brasileiro de Estudos de Saúde - CEBES - ISSN 0103-1104

Av. Brasil, 4036 - Sala 802 - Manguinhos - 21040-361 - Rio de Janeiro - RJ - Fones: |21| 3882-9140 e |21| 3882-9141 - FAX.: |21| 2260-3782 - revista@saudeemdebate.org.br

(C) Todos os direitos reservados para CEBES - Desenvolvido por Zanda Multimeios da Informação

0451/2014 - A Assistência Farmacêutica nas Redes de Atenção à Saúde: o planejamento e os serviços no SUS

The Pharmaceutical Services Networks in Health Care: planning and services in SUS 